\title{
Review \\ From Drosophila to Human: Biological Function of E3 Ligase Godzilla and Its Role in Disease
}

\author{
Valérie C. Cabana ${ }^{1,2}$ and Marc P. Lussier ${ }^{1,2, *(D)}$ \\ 1 Département de Chimie, Université du Québec à Montréal, Montréal, QC H2X 2J6, Canada; \\ cabana.valerie@courrier.uqam.ca \\ 2 Centre d'Excellence en Recherche sur les Maladies Orphelines-Fondation Courtois (CERMO-FC), \\ Faculté des Sciences, Université du Québec à Montréal, Montréal, QC H2X 3Y7, Canada \\ * Correspondence: lussier.marc@uqam.ca; Tel.: +1-514-987-3000 (ext. 5591); Fax: +1-514-987-4054
}

Citation: Cabana, V.C.; Lussier, M.P. From Drosophila to Human: Biological Function of E3 Ligase

Godzilla and Its Role in Disease. Cells 2022, 11, 380. https://doi.org/ 10.3390/cells 11030380

Academic Editor: Kwon-Yul Ryu

Received: 20 December 2021

Accepted: 20 January 2022

Published: 23 January 2022

Publisher's Note: MDPI stays neutral with regard to jurisdictional claims in published maps and institutional affiliations.

Copyright: (C) 2022 by the authors. Licensee MDPI, Basel, Switzerland. This article is an open access article distributed under the terms and conditions of the Creative Commons Attribution (CC BY) license (https:/ / creativecommons.org/licenses/by/ $4.0 /)$.

\begin{abstract}
The ubiquitin-proteasome system is of fundamental importance in all fields of biology due to its impact on proteostasis and in regulating cellular processes. Ubiquitination, a type of protein post-translational modification, involves complex enzymatic machinery, such as E3 ubiquitin ligases. The E3 ligases regulate the covalent attachment of ubiquitin to a target protein and are involved in various cellular mechanisms, including the cell cycle, cell division, endoplasmic reticulum stress, and neurotransmission. Because the E3 ligases regulate so many physiological events, they are also associated with pathologic conditions, such as cancer, neurological disorders, and immune-related diseases. This review focuses specifically on the protease-associated transmembrane-containing the Really Interesting New Gene (RING) subset of E3 ligases. We describe the structure, partners, and physiological functions of the Drosophila Godzilla E3 ligase and its human homologues, RNF13, RNF167, and ZNRF4. Also, we summarize the information that has emerged during the last decade regarding the association of these E3 ligases with pathophysiological conditions, such as cancer, asthma, and rare genetic disorders. We conclude by highlighting the limitations of the current knowledge and pinpointing the unresolved questions relevant to RNF13, RNF167, and ZNRF4 ubiquitin ligases.
\end{abstract}

Keywords: ubiquitin; Godzilla; RNF13; RNF167; ZNRF4; pathological dysfunction; E3 ligase; PA-TM-RING family

\section{Introduction}

Protein post-translational modification (PTM) refers to a modification of a polypeptide chain that occurs after its biosynthesis. These protein alterations typically require enzymes that catalyze either reversible or irreversible biochemical modifications and, thus, add another level of complexity and regulation to the proteome. It is clear from a vast array of studies that PTMs play crucial roles in influencing protein activity and, consequently, regulate the cellular functions and signaling pathways [1]. The array of PTMs includes chemical modifications, such as phosphorylation, modification by complex molecules, such as glycosylation, or peptide modification, such as ubiquitination [2].

Ubiquitination is a reversible PTM that involves the covalent addition of one or more ubiquitin $(\mathrm{Ub})$ molecules, a 76-amino acid protein, on a substrate's internal lysine via the formation of an isopeptide bond. The ultimate conjugation of $\mathrm{Ub}$ to a substrate requires the sequential action of a Ub-activating enzyme (E1), a Ub-conjugating enzyme (E2), and a Ub ligase enzyme (E3) [3,4]. The E1 generates a thioester bond between the cysteine at its active site and the $\mathrm{Ub} C$-terminal carboxyl group in an ATP-dependent process [4-6]. Through a transesterification reaction, the E2 catalyzes the transfer of $\mathrm{Ub}$ from the E1 to the cysteine residue in the active site of the E2 to form a $\mathrm{Ub} \sim \mathrm{E} 2$ conjugate [4-6]. Finally, the E3 promotes the discharge of $\mathrm{Ub}$ from the $\mathrm{Ub} \sim \mathrm{E} 2$ conjugate to promote the formation of an isopeptide bond between the acceptor lysine of the target protein and the $C$-terminal glycine 
of $\mathrm{Ub}$ [4-6] (Figure 1A). Ub contains seven lysine residues (K6, K11, K27, K29, K33, K48, and K63) and one methionine residue (M1), all of which can be targeted for Ub coupling, leading to distinct poly-Ub chains and an expanded "ubiquitin code" [3,7-14] (Figure 1B). For instance, whereas mono-ubiquitination is usually involved in endocytosis, DNA repair, and signal transduction, poly-ubiquitination is extremely diverse and is used for a variety of signals $[15,16]$. For example, the $\mathrm{K} 48$ chains are involved in proteasomal degradation, while the K63 chains are implicated in proteasome-independent signaling, such as endocytosis, protein kinase activation, and the DNA damage response [7,17,18]. Furthermore, the K29 chains are involved in lysosomal degradation, while the K11 chains are used to regulate endoplasmic reticulum-mediated degradation and cell cycle progression [13,14,19-21]. Importantly, Ub chain linkages may need editing and removal from the substrate proteins, a process requiring enzymes called deubiquitinases (DUBs) that exhibit specificity toward the different $\mathrm{Ub}$ chain linkage topologies and structures $[4,6]$.

A

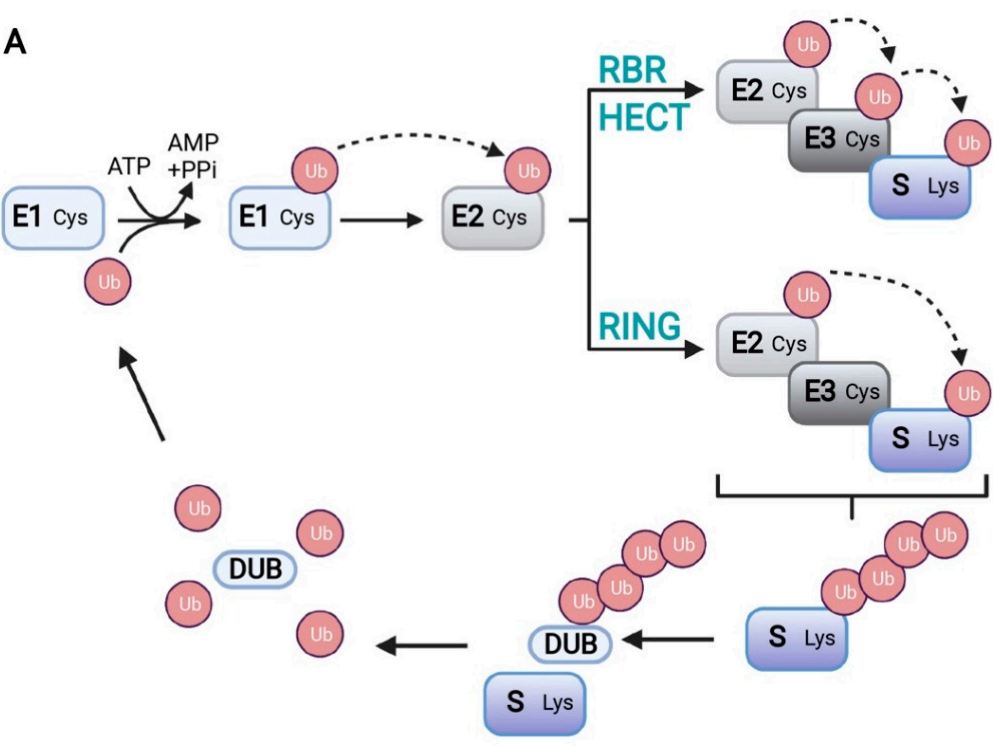

C

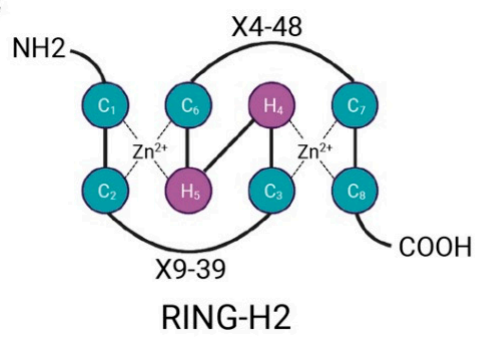

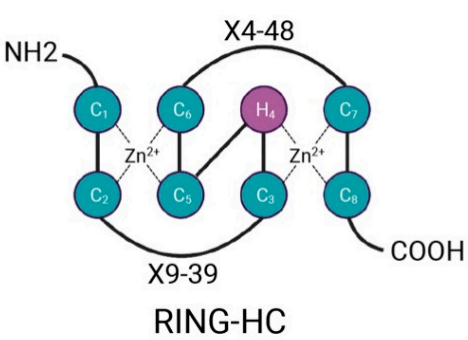

B
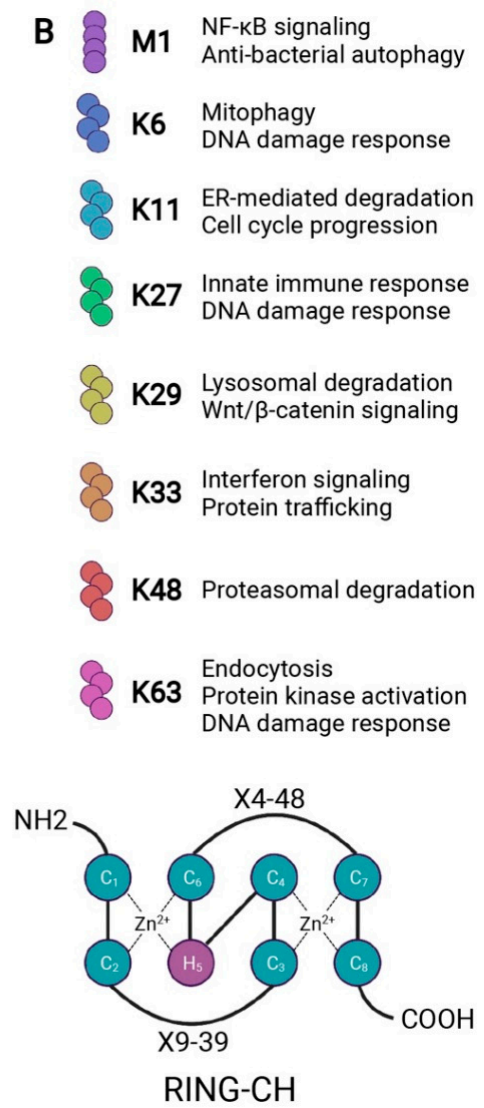

Figure 1. Schematic representation of the ubiquitination process. (A) Ubiquitination starts with an ATP-dependent step where the ubiquitin-activating enzyme (E1) creates a thioester bond between the cysteine residue at its active site and ubiquitin $(\mathrm{Ub})$. $\mathrm{Ub}$ is then transferred to the cysteine residue in the Ub-conjugating enzyme (E2) active site. Finally, Ub ligase (E3) transfers Ub to a lysine residue of the substrate (S). There are three types of E3s, as follows: RBR, HECT, and RING domains. RBR and HECT domain E3 ligases first transfer $\mathrm{Ub}$ to a cysteine residue of their active site before transferring it to the substrate. The RING domain directly transfers $\mathrm{Ub}$ from E2 to the substrate. Deubiquitinases (DUB) can remove, edit the length of, or disassemble a Ub chain to be recycled. (B) A description of the cellular function for the possible Ub chains formed through methionine (M)1 or lysine (K) 6, 11, $27,29,33,48$, or 63. (C) Schematic representation of the cross-brace arrangements of the RING-H2, RING-HC, and RING-CH finger motifs. Cysteine $(\mathrm{C})$ and histidine $(\mathrm{H})$ residues are numbered with their positions in the conserved zinc- $\left(\mathrm{Zn}^{2+}-\right)$ coordination sites. $\mathrm{X}$ represents any amino acid located in the polypeptide between the cysteines coordinating $\mathrm{Zn}^{2+}$. 
Deciphering the Ub code and its associated mechanisms is central to understanding the regulation of protein activity, cellular signaling, and cell physiology. One of the major lines of investigation that has motivated the $\mathrm{Ub}$ research community over the last decade is to uncover how genetically inherited errors can lead to devastating diseases. For instance, important advances have demonstrated genetic links in Angelman syndrome (caused by maternal deficiency of the E6-AP Ub E3 ligase), juvenile recessive Parkinson's disease (caused by mutations in the gene encoding Parkin-Ub E3 ligase), and autoimmune polyendocrine syndrome type I (caused by mutations in the gene encoding the AIRE Ub E3 ligase) [22]. The E3 ligases are a distinct group of enzymes that are crucial to the ubiquitination process as they control the specificity of the reaction towards a targeted protein.

To date, more than 600 genes encoding E3 ligases have been identified in the human genome $[3,4,8]$. Based on their catalytic core domain, E3 ligases are architecturally diverse and are categorized according to their functional domain consisting of either a Homologous to E6-AP C-Terminal (HECT) domain, a Really Interesting New Gene (RING) domain, or a RING-Between-RING (RBR) domain [6] (Figure 1A). Specifically, the HECT-type E3s catalyze $\mathrm{Ub}$ transfer from $\mathrm{Ub} \sim \mathrm{E} 2$ to a substrate via their active-site cysteine residue [4-6]. In contrast, a RING-type E3 does not possess an active cysteine in its functional RING domain and, thus, mediates the transfer of $\mathrm{Ub}$ to the substrate protein from the Ub-charged E2. Importantly, this family harbors a zinc-binding domain termed the RING, or the U-box domain, as the platform required to associate with Ub E2s. Finally, RBR-type E3s are considered to be a hybrid of the HECT and RING domains since these enzymes function by using an E2-binding RING structure and a second RING domain that contains an active cysteine for the formation of an intermediate $\mathrm{E} 3 \sim \mathrm{Ub}$ conjugate before the transfer of $\mathrm{Ub}$ to a substrate [6,23].

While there are about 30 HECT domain E3 proteins in mammals, there are more than 300 potential RING finger-encoding proteins in the human genome [24,25]. Of those, about 50 are predicted to have hydrophobic regions corresponding to transmembrane (TM) domains [24,26]. The TM-containing RING finger proteins can be further divided into subfamilies that include the tripartite motif-containing (TRIM), the protease-associated (PA) transmembrane RING (PA-TM-RING), the RBR, and the membrane-associated RING$\mathrm{CH}$ (MARCH) proteins. Except for the presence of a RING finger domain, these four transmembrane RING finger-containing protein families share little sequence homology and have diverse subcellular localizations and functions [26].

The presence of an N-terminal putative signal peptide (SP), a PA domain, a single TM domain, and a RING-H2 finger domain characterize the PA-TM-RING family [26,27]. The signal peptide allows the targeting of the protein to the secretory pathway. This region of the protein has yet to be adequately studied for most, if not all, of the members of this family [28]. The PA domain is a conserved sequence of about 120 amino acids implicated in protein-protein interactions $[27,29]$. It was initially identified in non-catalytic regions of plant vacuolar sorting receptors and zinc-containing metalloproteases, but the exact role of this domain in the PA-TM-RING family of Ub ligases remains unclear [27,30]. The single TM domain is composed predominantly of nonpolar amino acid residues and is required for anchoring the protein in the membrane [31]. The RING finger domain is divided into subgroups based on the presence of cysteine $(\mathrm{C})$ and histidine $(\mathrm{H})$ residues in the fourth and fifth positions of the catalytic domain [26]. The RING-HC domain is composed of a $\mathrm{C}_{3} \mathrm{HC}_{4}$, the RING-H2 has a $\mathrm{C}_{3} \mathrm{H}_{2} \mathrm{C}_{3}$ sequence, and the RING-CH contains a $\mathrm{C}_{4} \mathrm{HC}_{3}[26,32]$ (Figure 1C). The PA-TM-RING family has a RING-H2 finger domain with two characteristic histidines in the fourth and fifth positions of the conserved $\mathrm{Zn}^{2+}$-coordination sites [26,32].

The PA-TM-RING family is present in Drosophila melanogaster where it is known as the Goliath Ub Ligase family, with only two members, Goliath and Godzilla. While these two are the only representatives of the PA-TM-RING family in Drosophila melanogaster, there are nine predicted homologues in humans. RNF133, RNF148, RNF128/GRAIL, RNF130, RNF150, and RNF149 are closely related to Goliath whereas RNF167, RNF13, and ZNRF4 are homologs of Godzilla [33] (Figure 2). The Goliath gene was first identified in 1987 
and was shown to be a transcription factor involved in Drosophila embryo mesoderm formation [34,35]. It was later demonstrated to be enriched after Notch activation and was predicted to be active in fusion-competent myoblasts [36]. Since the Goliath gene expression is restricted to embryonic muscle, the Drosophila Goliath null mutants are viable and fertile $[33,36]$.

\section{Godzilla}
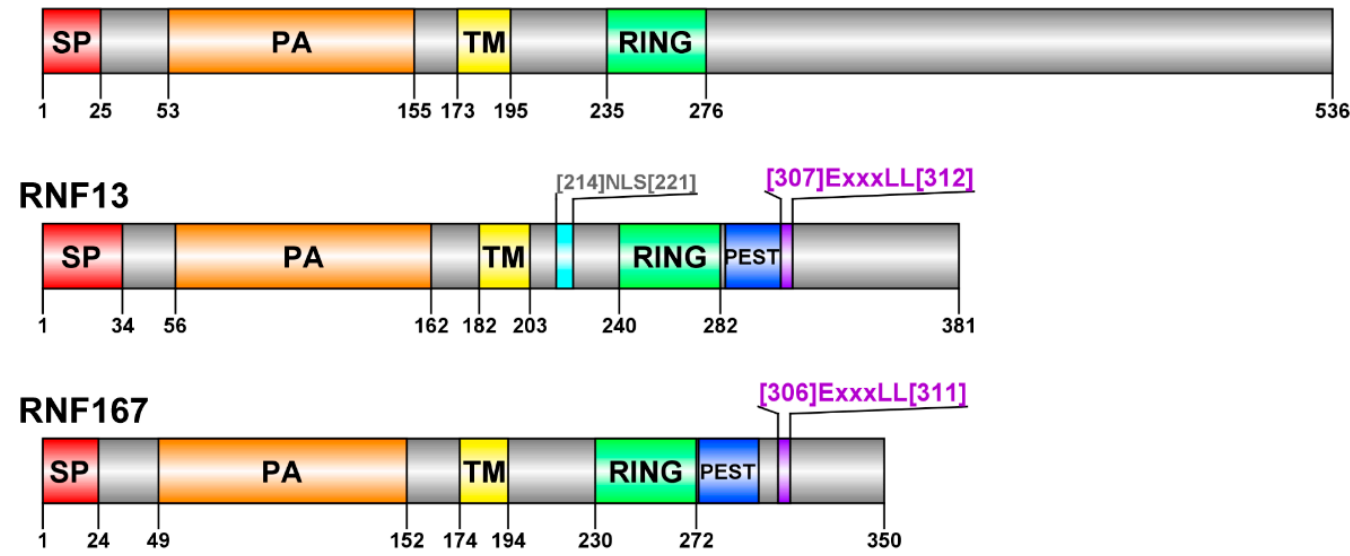

\section{ZNRF4}

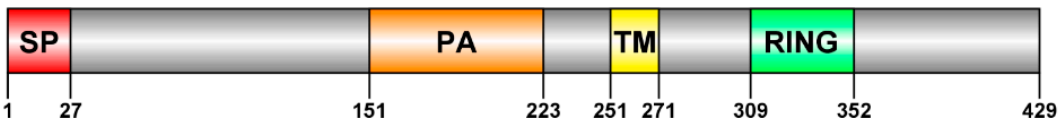

Figure 2. Schematic domain structure of Drosophila Godzilla, human RNF13, human RNF167, and human ZNRF4 proteins. SP, signal peptide (in red); PA, protease-associated domain (in orange); TM, transmembrane domain (in yellow); NLS, nuclear localization signal (in light blue); RING, RING domain (in green); PEST, PEST domain (in deep blue); ExxxLL, dileucine motif (in purple). Graphical representations were generated with DOG 2.0.1: Illustrator of Protein Domain Structures [37].

While much is known about the human Goliath homologues, such as the role of RNF128 in immune tolerance [38-40], this review will exclusively focus on Godzilla and its human homologues. First, we will address the Godzilla function in Drosophila and then present the cellular localization, function, and pathological dysfunction for Godzilla's human homologues, RNF167, RNF13, and ZNRF4. For instance, hundreds of singlenucleotide variation (SNV) mutations for RNF167, RNF13, and ZNRF4 have been reported in cancer. Finally, we will highlight some of the remaining questions about these proteins.

\section{Godzilla}

The Godzilla gene was first discovered in 2000 when Adams et al. determined the nucleotide sequence of nearly all of the euchromatic portion of the Drosophila genome [41]. Godzilla is universally expressed in Drosophila, and alterations to this locus are larval lethal [33]. The Godzilla protein sequence includes the characteristic domains of the family (Figure 2). When exogenously expressed in mammalian human embryonic kidney 293 (HEK293T) cells, Godzilla significantly co-localized with the early endosomal marker Early Endosome Antigen 1 (EEA1). This is concordant with the observations of endogenous Godzilla protein overlapping with endosomes in Drosophila tissues [33]. Furthermore, exogenous expression of Godzilla resulted in enlarged endosomes and a loss of Mannose-6Phosphate (M6P) receptor staining, suggesting that the Godzilla expression could perturb the endosomal maturation process [33]. However, the use of the Godzilla Ub ligasedead mutant (DN for dominant-negative) did not result in enlarged endosomes, implying that Godzilla's impact on endosomal maturation is through RING-dependent substrate ubiquitination [33]. 


\subsection{Godzilla's Substrate Regulates Recycling Endosomes}

The vesicle-associated membrane protein 3 (VAMP3), a member of the Soluble Nethylmaleimide-sensitive-factor Attachment protein Receptor (SNARE) family, is a substrate for Godzilla [33]. Specifically, the enlarged endosome phenotype observed with Godzilla overexpression in HEK293T cells was blocked both by abrogating the VAMP3 activity via small interfering RNA (siRNA) and by the use of VAMP3 mutants that could not be ubiquitinated in HEK293T cells, implicating VAMP3 ubiquitination by Godzilla in the regulation of SNARE-dependent fusion [33]. Knowing that VAMP3 is involved in the exocytosis of recycling endosomes [42,43], the presence of Rab11-positive recycling vesicles, which normally exhibit a pericentriolar location, was analyzed in Godzilla-transfected cells [33]. Wild-type (WT) Godzilla-expressing cells showed residual Rab11 staining in the vicinity of the enlarged endosomes, meaning that the Rab11-containing vesicles were unable to properly form in the presence of Godzilla [33]. Interestingly, the DN Godzilla did not induce the same phenotype, suggesting that the impact on recycling endosomes is through RING-dependent ubiquitination [33]. Furthermore, transferrin internalization was delayed in the cells expressing the active form of Godzilla, in contrast to the DN Godzilla, further supporting the role of Godzilla in the regulation of recycling endosome trafficking [33]. Importantly, the knockdown of the Drosophila homologue of VAMP3, Synaptobrevin (Syb), in Drosophila wing disc led to results similar to those described above, confirming the role of Godzilla in vivo [33].

\subsection{Wingless Transcytosis}

Usually, to prevent extracellular protein transfer, the apical and basolateral membranes of epithelia are insulated from each other [44]. Transcytosis is the vesicular transport process that allows proteins to cross the cellular barriers [44]. Interestingly, a role for Godzilla was uncovered in Wingless transcytosis where Godzilla promotes signaling in Drosophila wing imaginal discs [45]. Yamazaki et al. have found that Wingless is first produced apically before being transcytosed to the basolateral surface, where it engages in a signaling pathway [45]. The authors demonstrated that this transcytosis is dependent on Godzilla [45]. Godzilla knockdown led to the loss of the wing margin, a reduced expression of Senseless, which is a target of Wingless signaling, and the accumulation of intracellular Wingless in the cellular apical region [45]. In agreement with the preceding demonstration that Godzilla ubiquitinates Syb [33], Syb mutants and Syb knockdown led to a similar phenotype as the one observed in the Godzilla knockdown cells [45]. Overall, these studies suggest that Godzilla has important roles in regulating recycling endosome trafficking and in Wingless transcytosis through the ubiquitination of the Syb protein [33,45].

\section{RNF13}

Ring Finger Protein 13 (RNF13) was first identified in 1996 as chicken RING zinc finger (C-RZF) when Tranque et al. studied the changes in gene expression following tenascin- $C$ treatment in chicken embryo brains [46]. They found that the C-RZF gene expression was upregulated, but the implication of this effect is still unknown [46]. The RNF13 sequence includes the characteristic domains of the PA-TM-RING family, in addition to a PEST domain (described below), a nuclear localization signal (NLS), and a canonical [D/E]xxxL[L/I] motif (Figure 2) [47]. Until now, the mammalian RNF13 protein mostly has been localized to the endoplasmic reticulum (ER), Golgi, late endosomes, lysosomes, and the plasma membrane [27,47-50].

\subsection{Protein Domains}

\subsubsection{PEST Domain}

An intriguing region within RNF13 is the PEST domain, which contains a high number of proline $(\mathrm{P})$, glutamic acid $(\mathrm{E})$, serine $(\mathrm{S})$, and threonine $(\mathrm{T})$ residues usually, but not always, with clusters of several positively charged amino acids that promote the rapid degradation of short half-life proteins [51]. The short half-life of RNF13 was hypothesized 
to be associated with its PEST domain. Specifically, it was demonstrated that the exogenous expression of RNF13 in Chinese hamster ovary (CHO) cells was barely detectable unless the cells were treated with the proteasomal inhibitor MG132 [47,50]. Interestingly, RNF13 abundance was stabilized in the cells treated with the protein kinase $C$ (PKC) agonist phorbol 12-myristate 13-acetate (PMA), increasing RNF13's half-life similar to that of MG132 [50]. However, to the best of our knowledge, no study has evaluated the implication of the PEST domain in RNF13 protein turnover and, specifically, whether MG132 or PMA treatment act through this domain to increase RNF13's half-life.

\subsubsection{Nuclear Localization Signal}

RNF13 appears to possess an NLS, but with an undetermined function. The treatment of HeLa cells with PMA caused RNF13 to be targeted to the inner nuclear membrane (INM) [50], suggesting a potential nuclear role for the protein in response to some cellular signals [50]. Mechanistically, RNF13 targeting to the INM requires the protein to first traffic through the endosomes [50]. RNF13 undergoes extensive proteolysis in order to release both the PA- and the RING-domains from the membrane [47]. However, the role of RNF13 in the nucleus, and why it undergoes such proteolytic events, remain to be elucidated.

\subsubsection{Di-Leucine Sorting Signal}

Another region of interest in the RNF13 protein sequence is the presence of a canonical [D/E]xxxL[L/I]-type di-leucine sorting signal. This region binds to adaptor protein (AP) complexes to allow proper sorting, targeting, and routing of a transmembrane protein, such as RNF13, within the secretory pathway and endolysosomal compartments [52,53]. Recent studies using affinity-purification and mass spectrometry analyses [54-56] have identified an interaction between RNF13 and AP-1, an AP complex associated with the trans-Golgi network, and with early and recycling endosomes [57,58]. It was also found that RNF13 associates with AP-3 [54-56], which mediates the transport from the tubular endosomes to the late endosomes and lysosomes and is therefore involved in the biogenesis of lysosome-related organelles [57,58]. Accordingly, our own work demonstrates that RNF13 interacts with the AP-3 complex in HEK293T cells [59], an interaction disrupted by an APbinding defective RNF13 mutant. By replacing the leucines with alanines in the di-leucine motif (i.e., L311A/L312A), the lysosomal localization of RNF13 was altered, suggesting that RNF13's di-leucine sorting signal motif is crucial for the lysosomal targeting of the protein [59]. Correspondingly, the knockdown of AP-3 altered the lysosomal localization of WT RNF13 and led to an alteration in the endosomal vesicle size [59]. Overall, this suggests that RNF13 might go into the endolysosomal compartments through an AP-3 dependent pathway. Future studies are critical to clarify the mechanism leading to the endolysosomal localization of RNF13 [59].

\subsection{Cellular Functions}

\subsubsection{Neurobiological Role}

Over the years, RNF13 expression has been associated with neurobiological functions. For instance, the ectopic expression of RNF13 allows the spontaneous growth of neurites in PC12 cells, which is similar to the nerve growth factor treatment of these cells [60]. In addition, RNF13 mRNA expression doubled in the B35 cells when they were treated with dibutyryl-cAMP [47]. Together, these studies implicate RNF13 in neurodevelopment. Accordingly, evidence shows that RNF13 gene expression in humans is ubiquitous, but higher in the brain, cerebellum, spinal cord, and testis $[47,60,61]$. Interestingly, a study using RNF13 knockout mice displaying a deficit in learning showed that the synaptic vesicle density decreased while the active zone size increased, suggesting that these observations resulted from the impaired SNARE complex assembly [62]. The study also demonstrates that RNF13 ubiquitinates SNARE-associated protein (snapin) to allow its interaction with Synaptosome associated protein 25 (SNAP-25) to strengthen the SNARE complex [62]. Co-immunoprecipitation assays demonstrated that RNF13 knockout mice have decreased 
interaction between snapin/SNAP-25, Vamp-2/SNAP-25, Synaptotagmin/SNAP-25, and Synaptotagmin/Vamp-2, suggesting that RNF13 plays a critical role in synaptic neurotransmission [62]. Interestingly, while the authors reported K29-linked polyubiquitination of snapin by RNF13, increasing snapin protein expression was correlated in a linear relationship with higher RNF13 protein expression, suggesting that RNF13 does not promote snapin degradation [62]. While K29 polyubiquitination has been reported to regulate some kinase activities, the role for RNF13-mediated snapin K29-linked Ub chains remains to be elucidated [63].

\subsubsection{Cell Migration and Invasiveness}

In addition to its implication in neurobiology, RNF13 has been associated with tumorigenesis, ER stress, and myogenesis $[48,49,64,65]$. In pancreatic cancer, the overexpression of WT, but not DN, RNF13 in MiaPaca-2 cells led to increased matrix metallopeptidase 9 (MMP-9) activity, suggesting that the Ub ligase activity of RNF13 promotes metalloprotease function and cell invasion [49]. In contrast, RNF13 knockout mice implanted with a pulmonary metastatic cancer cell model did not have a difference in tumor size when compared to their WT littermates, but the WTs exhibited a larger metastatic area in the lung [66]. Interestingly, this study shows that RNF13 knockout mice had a reduced granulocyte macrophage colony-stimulating factor (GM-CSF) concentration in the lung, suggesting that RNF13 reduces the colonization of metastases through the regulation of GM-CSF concentration [66]. Whereas the molecular mechanism of RNF13 regulation of GM-CSF concentration is not yet understood, it is well known that invasion is the first step to metastasis formation while the host microenvironment is key to establishing the final fate of the tumor cells [66]. Thus, it is possible that a higher expression of RNF13 leads to enhanced invasiveness but also reduces the likelihood of metastatic colonization. In order to shed light on the discrepancy of these two studies $[49,66]$, future studies will need to dissociate the function of RNF13 at the protein network level (i.e., with various interactors) and the Ub ligase activity.

\subsubsection{ER Stress}

An important implication in cellular apoptosis has been reported for RNF13. Specifically, the ectopic expression of RNF13 increases apoptosis while RNF13 knockdown led to cell resistance to apoptosis, induced by treatment using the PKC inhibitor staurosporine (STS) [48]. Specifically, RNF13 ectopic expression in SHSY-5Y cells increased the amount of spliced X-Box Binding Protein 1 (XBP1), a result similar to that of ER stress induction using tunicamycin [48]. Conversely, RNF13 knockdown reduced both the amount of spliced XBP1, phosphorylated c-Jun N-terminal kinase (JNK), and phosphorylated c-Jun in cells treated with tunicamycin [48]. The authors also demonstrated that RNF13 interacts with inositol-requiring enzyme $1 \alpha$ (IRE1 $\alpha)$. The ectopic expression of RNF13 increases the IRE1 $\alpha$ phosphorylation, suggesting that RNF13 regulates ER stress-induced apoptosis through the activation of the IRE1 $\alpha$-TNF receptor-associated factor 2 (TRAF2)-JNK signaling pathway [48]. Supporting this idea, a cycloheximide chase experiment demonstrated that the RNF13-IRE1 $\alpha$ interaction increased the half-life and the stability of IRE1 $\alpha$ [67].

\subsubsection{Myogenesis and Muscle Regeneration}

The role of RNF13 in myogenesis has only been studied in chickens and mice $[65,68]$. Specifically, myostatin, a negative regulator that inhibits myoblast proliferation and differentiation, induces C-RZF gene expression in chicken fetal myoblasts (CFM) [65]. The analysis of the temporal pattern of the C-RZF protein has revealed that it was highly expressed in embryonic skeletal muscle, but rapidly decreased to almost undetectable levels at one week after hatching [65]. Furthermore, ectopic expression of C-RZF in CFM led to a reduced cell number. An important experiment using $\left[{ }^{3} \mathrm{H}\right]$-thymidine incorporation suggested that the decreased cell number was not a result of increased cell death, but more likely an inhibitory effect of C-RZF on CFM proliferation [65]. Following this idea, the 
authors looked at the expression of $\mathrm{MyoD}$ and Caveolin-3, two myogenic regulatory factors. They found that both MyoD and Caveolin-3 were downregulated in C-RZF-overexpressing CFM, suggesting that C-RZF could act as a negative regulator of muscle cell proliferation. To our knowledge, whether human RNF13 has a similar function remains to be seen [65].

Another study has investigated the function of RNF13 in cardiotoxin (CTX)-induced skeletal muscle regeneration. The results show that after CTX damage, RNF13 knockout mice had more regenerating fibers in their tibialis anterior (TA) muscles than their WT littermates [68]. Likewise, satellite cell proliferation was also accelerated while cytokines interleukin-4 (IL-4) and interleukin-6 (IL-6) were upregulated after muscle damage in the CTX-treated RNF13 knockout mice [68]. Although the study did not explain how RNF13 acts on these cytokines, the use of neutralizing antibodies against those two cytokines slowed the regeneration process in the CTX-treated RNF13 knockout mice, suggesting that the effect of RNF13 on cell proliferation involves a tight regulation of IL-4 and IL-6 levels [68].

\subsection{Pathological Dysfunctions Associated with RNF13}

\subsubsection{Cancer}

One study investigated some of the RNF13 variants identified in tumor samples [27]. While the overexpression of RNF13 WT proteins induced giant endosomes in HEK293T cells, only the variants located within the PA or RING domain lost the ability to induce this phenotype [27]. Interestingly, the point mutations in the RING domain allowed RNF13 to retain its endosomal localization, while the mutations in the PA domain did not [27]. Furthermore, altered RNF13 expression has been linked to cancer. Indeed, RNF13 expression is downregulated in uveal melanoma [69], while RNF13 expression was found to be significantly higher in pancreatic ductal adenocarcinoma (PDAC) than in normal, healthy pancreatic tissue [49]. The upregulated RNF13 expression was shown to be associated with histological grading, and the positive staining of RNF13 was mostly found in welldifferentiated tumors [49].

\subsubsection{Atherosclerotic Plaques}

RNF13 altered expression is not only linked to cancer. In fact, recent studies have shown that RNF13 gene expression is upregulated in atherosclerotic plaques [70] and downregulated in asthma [71]. Also, Huang et al. discovered that the microRNA miR-32$3 p$ regulates the expression of RNF13 [72]. Specifically, the expression of miR-32-3p was downregulated in cells that were treated with oxidized low-density lipoprotein (ox-LDL) and TNF- $\alpha$ to simulate an ER stress model, as observed in atherosclerosis [72]. Under the same conditions, RNF13 mRNA expression and protein abundance were upregulated [72]. In addition, ectopic expression of RNF13 in the presence of ox-LDL and TNF- $\alpha$ led to an increase in stress-induced apoptosis [72]. Interestingly, bioinformatics analysis revealed that miR-32-3p was also downregulated in patients with acute myocardial infarction [72]. In an atherosclerotic plaque model in rats, it was found that the inhibition of miR-32-3p led to higher RNF13 expression, an upregulation of ER stress-related proteins, higher arterial plaque instability, a lower survival rate, and increased pathological lesions in the arterial tissue. These results suggest that RNF13 might be involved in atherosclerotic plaques via its role on ER stress-induced cell apoptosis [72].

\subsubsection{Parkinson's Disease}

A recent study demonstrated that silencing RNF13 could alleviate the symptoms in a Parkinson's disease mouse model [73]. Specifically, the injection of a short hairpin RNA specific for RNF13 (shRNF13) with an intraperitoneal injection of 1-methyl-4-phenyl-1,2,3,6tetrahydropyridine (MPTP) to induce the Parkinson's disease model demonstrated that the group with the silenced RNF13 showed improved motor coordination when compared to an MPTP model only [73]. Importantly, the apoptosis of neurons in the substantia nigra was reduced in shRNF13 + MPTP when compared to MPTP alone. Interestingly, the authors 
measured a significant reduction in the protein abundance for the different components of the IRE1 $\alpha$-TRAF2-Apoptosis signal-regulating kinase 1 (ASK1)-JNK pathway [73]. Furthermore, dopaminergic neurons in the substantia nigra pars compacta had significantly more immunohistochemical staining of tyrosine hydroxylase-immunoreactive (TH-IR) in the neurons from the MPTP + shRNF13 mice when compared to MPTP alone [73]. Overall, this study suggests that reducing the activation of the IRE1 $\alpha$-TRAF2-ASK1-JNK pathway by silencing RNF13 might be beneficial to alleviate some of the motor dysfunction and to prevent the dopaminergic neuron damage in a Parkinson's disease mouse model [73].

\subsubsection{Developmental and Epileptic Encephalopathy 73}

Edvardson et al. reported three unrelated individuals with developmental and epileptic encephalopathy 73 (DEE73, OMIM \#618379) carrying a de novo heterozygous mutation in the gene encoding RNF13 (c.932T $>C$ [p.L311S] and c.935T $>C$ [p.L312P]) [74]. These individuals had clinical features including, but not limited to, microcephaly, feeding difficulties, failure to thrive, restlessness, refractory epilepsy, cortical visual impairment, bilateral hearing loss, scoliosis, and a profound intellectual disability [74]. In this report, fibroblast and lymphoblast cells derived from an affected individual carrying the RNF13 variant L311S were treated with tunicamycin to induce ER stress [74]. The results showed that both spliced XBP1 and phosphorylated c-Jun were increased in the treated cells from the affected individual compared to an unrelated control, suggesting that the mutated cells had enhanced ER stress-induced apoptosis signaling [74]. Although this seminal study provided important evidence regarding the biological implication of expressing RNF13 variant L311S, it did not address the fact that the identified variants L311S and L312P completely altered RNF13's [D/E]xxxL[L/I]-type di-leucine sorting signal. In our own study, we demonstrated that both RNF13 L311S and L312P variants disrupted the association with AP-3 [59]. Notably, both RNF13 L311S and L312P variants no longer localized in the lysosomes, although they changed the morphology of the endolysosomal vesicles [59]. While we don't yet know the exact molecular mechanism involved and how it is linked to the increased apoptosis markers described by Edvardson et al., our results suggest that RNF13 L311S and L312P disrupt the endolysosomal pathway due to the loss of interaction with the AP-3 complex $[59,74]$. Future studies will need to pinpoint the molecular and cellular mechanisms that are altered by the presence of the RNF13 variants and to investigate the possibility that enhanced ER stress-induced apoptosis signaling may reflect an altered endolysosomal function.

\section{RNF167}

Ring Finger Protein 167 (RNF167), initially named RING105 [75], was first isolated in a bacterial two-hybrid screen with hCdc34/UbcH3 as bait [75]. The RNF167 sequence (Uniprot Accession Q9H6Y7) includes the characteristic domains of the PA-TM-RING family, along with a PEST domain (Figure 2) [75]. As for RNF13, the presence of the PEST domain in RNF167 could indicate a short half-life of the protein. Accordingly, the ectopically expressed WT RNF167, but not DN RNF167, is rapidly degraded in both HeLa and HEK293T cells in a process sensitive to the proteasome inhibitor MG132, which inhibits the degradation of the protein [75]. The experiments performed in our laboratory do not support the statement related to MG132, and the reason for this discrepancy is unclear. Similar to RNF13, RNF167 includes a canonical di-leucine motif that has never been studied. Interestingly, affinity-purification and mass spectrometry analyses $[55,56]$ demonstrate that RNF167 interacts with AP-3, which supports the previous studies describing RNF167 localization in late endosomes and lysosomes [27,76-78]. Future molecular studies will likely define the importance of the di-leucine motif in RNF167 trafficking to endolysosomal compartments. 


\subsection{Expression}

The RNA expression of RNF167 in various tissues has been reported in the literature and, intriguingly, is highly divergent. For instance, using qPCR on Human Total RNA Master Panel II, RNF167 expression was elevated in the brain, fetal brain, cerebellum, and testis but was low in the pancreas [61]. On the other hand, using Human MTC Panel I and II, RNF167 expression was reported to be higher in the liver, pancreas, and testis, while being lower in the brain [76]. Although both of these studies show that RNF167 is ubiquitously expressed, the divergence may be associated with the normalization of the samples [61,76]. Importantly, RNF167 protein abundance in tissue was verified and found to be higher in the kidney and liver of human tissues [75]. In the rodent brain, the cortex and hippocampus express similar levels of the RNF167 protein [76] in the detergent soluble synaptosome membrane fraction but excluded from the postsynaptic density [77].

\subsection{Neurotransmission Modulator}

In the brain, RNF167 is an important regulator of excitatory neurotransmission [76,77]. The expression of either WT or DN RNF167 in neurons (endogenous expression), and in HEK293T (ectopic expression), did not affect the total protein abundance of $\alpha$-amino-3hydroxy-5-methyl-4-isoxazole propionic acid (AMPA) receptor (AMPAR) subunits GluA1 or GluA2 [76]. However, the surface expression of GluA2, a subunit of the AMPAR that plays a major role in excitatory synaptic transmission, was highly increased in the neurons that were infected with lentiviruses expressing DN RNF167 or shRNAs designed to knockdown endogenous RNF167 [76]. The alteration of RNF167 activity led to an increase in evoked excitatory postsynaptic AMPAR currents (AMPAR-EPSCs) at the Schaffer collateral/CA1 synapses [76]. This phenotype could be rescued by RNF167 WT overexpression [76]. Overall, these results suggest that ubiquitination of GluA2 controls its surface expression and RNF167 regulates the neuronal synaptic strength [76].

To better understand the mechanisms underlying RNF167-mediated AMPAR ubiquitination and how it affects AMPAR synaptic targeting, Ghilarducci et al. characterized the interaction between Ub-conjugating E2 enzymes (E2s) and RNF167 [77]. Using in vitro ubiquitination, it was demonstrated that RNF167 could functionally interact with approximately fifteen E2s [77]. Interestingly, UBE2D1-4 and UBE2N interact with RNF167 WT with dissociation constants in the high nanomolar range [77]. Immunofluorescence microscopy confirmed that E2s and RNF167 were localized in the same intracellular compartment, and the ability of RNF167 to interact with and ubiquitinate GluA2 was demonstrated using in vitro binding and ubiquitination assays [77]. Interestingly, using a two-step in vitro ubiquitination assay, it was shown that UBE2D1 is first needed for mono-ubiquitination before the complex UBE2N/UBE2V1 can promote poly-ubiquitination of GluA2 in an RNF167-dependent manner [77]. Ultimately, the AMPA agonist-induced GluA2 ubiquitination in the hippocampal neurons was reduced in the cells that were pretreated with a UBE2N/UBE2V1 complex inhibitor, suggesting that the UBE2N/UBE2V1 enzymatic complex is involved in activity-dependent GluA2 ubiquitination [77]. Due to the fact that AMPARs are modified with a $\mathrm{K} 63-\mathrm{Ub}$ chain [79] and that UBE2N is responsible for assembling this chain [5], it is highly plausible, but remains to be clearly demonstrated, that RNF167 catalyzes the formation of a K63-specific polyubiquitination chain on GluA2.

\subsection{Substrates Regulate Endosomal Trafficking and Lysosome Positioning}

In addition to neuronal function, RNF167 also regulates endosomal trafficking and lysosome positioning [33,78,80]. The exogenous expression of RNF167 in HEK293T led to a phenotype similar to the overexpression of Godzilla, which caused enlarged EEA1positive early endosomes and a loss of Rab11-positive recycling endosomes [33]. This study was the first to demonstrate the RNF167-dependent ubiquitination of Vamp3, suggesting that RNF167 regulates endosomal recycling in a manner similar to Godzilla [33]. A few years later, a proximity-dependent biotin labelling approach led to the identification of the ADP-ribosylation factor-like protein 8B (Arl8B) as a new substrate for RNF167 [78]. 
RNF167 targets Arl8B for degradation via the proteasome-dependent pathway in HeLa cells [78]. The level of Arl8B protein decreased when the RNF167 protein level increased, and this effect on the Arl8B protein abundance was inhibited by MG132 treatment or by the depletion of RNF167 using RNF167-specific siRNAs [78]. Knowing that Arl8B regulates lysosome localization and the knockdown of Arl8B causes the perinuclear clustering of lysosomes, the study showed that lysosomes were clustered in the perinuclear region in the presence of RNF167 WT but not DN [78]. Specifically, they demonstrated that RNF167 caused the clustering of the lysosomes in the presence of Arl8B WT, but not with the K141R mutant that could not be ubiquitinated, suggesting a role of RNF167 in lysosome positioning through Arl8B degradation [78]. Accordingly, the exogenous expression of RNF167 delays epidermal growth factor receptor (EGFR) degradation in contrast to siRNF167, which increases the degradation rate [78]. Specific siRNAs against Vamp3 and Arl8B also demonstrated that Vamp3 did not influence EGFR degradation while the knockdown of Arl8B recapitulates the RNF167 overexpression phenotype, suggesting that Arl8B degradation by RNF167 inhibits the EGFR trafficking to lysosomes [78].

Another study demonstrated that RNF167 must localize to lysosomes in order to induce perinuclear clustering because a PA-truncated RNF167 protein or a shorter isoform of RNF167 that does not localize to lysosomes did not induce the phenotype [80]. In another set of experiments, the overexpression of p50-Dynamitin, which disrupts the dynein-dynactin complex, and the inhibition of dynein with ciliobrevin both led to an increase in the peripheral distribution of lysosomes, suggesting that perinuclear clustering is dynein dependent [80]. In conditions promoting lysosomal exocytosis, RNF167-transfected cells display a substantial reduction in the surface expression of lysosomal-associated membrane protein 1 (Lamp1) when compared to controls, suggesting that RNF167 regulates lysosomal exocytosis [80]. In addition, RNF167 overexpression increased the amount of propidium iodide (PI) stained cells, signifying that the plasma membrane was neither intact nor repaired after streptolysin-O (SLO) treatment-induced pore formation in the plasma membrane [80].

\subsection{Pathological Dysfunctions Associated with RNF167 Cancer}

In addition to the identification of the RNF13 variants in tumor samples, some RNF167 variants were identified and characterized as well [27]. Similar to the results of RNF13, RNF167's variants, located within the PA or RING domain, abrogated the ability to induce giant endosomes in HEK293T cells [27]. Also, the authors demonstrated that RNF167 PA domain variant V98G, when co-expressed with WT RNF167, inhibits the formation of giant endosomes, therefore suggesting that the RNF167 V98G variant acts as a dominantnegative protein [27]. In another study, the K97N mutation in the PA domain was the only variant that did not induce lysosomal perinuclear clustering while increasing the surface expression of Lamp1, supporting the idea that RNF167 K97N increases lysosomal exocytosis [80]. Furthermore, cells overexpressing RNF167 K97N that were treated with SLO and $\mathrm{Ca}^{2+}$ to induce pore formation before allowing membrane resealing had lower PI staining than with WT RNF167, suggesting that the variant enhanced plasma membrane repair [80]. Overall, these studies suggest that PA domain variants of RNF167 found in tumor samples are mislocalized and might act as dominant negatives.

In an early study, it was reported that RNF167 polyubiquitinates Tumor-Suppressing Subchromosomal Transferable Fragment cDNA (TSSC5), a tumor suppressor, to degrade it via the proteasome pathway [75]. In this specific study, ectopically expressed RNF167 delays the G1-to-S transition in HeLa cells [75]. While the exact function of RNF167 in TSSC5 regulation is far from being understood [75], another study implicates RNF167 in cancer through the mammalian target of rapamycin complex 1 (mTORC1) [81]. RNF167 polyubiquitinates the protein Cytosolic arginine sensor for mTORC1 subunit 1 (CASTOR1) with a K29-linked Ub chain, which inhibits mTORC1 activation upon arginine deprivation, to promote CASTOR1 proteasomal degradation [81]. Interestingly, phosphorylation of CAS- 
TOR1 by the serine/threonine kinase AKT1 enhances the interaction between CASTOR1 and RNF167 [81]. Additionally, cells ectopically expressing RNF167 became insensitive to the arginine-mediated mTORC1 activation due to CASTOR1 degradation [81]. The phosphomimetic variant of CASTOR1, which causes lower CASTOR1 protein abundance, did not inhibit mTORC1 activation, tumor growth, or cell proliferation. The variant also led to a lower survival rate, suggesting that RNF167-mediated degradation leads to enhanced mTORC1 activation, cell proliferation, and tumorigenesis [81]. In vivo, high expression of RNF167 in breast tumors correlates with poor survival in human epidermal growth factor receptor 2 positive (HER2+) breast cancer while lower CASTOR1 expression was correlated with poor survival in estrogen receptor-positive (ER+) breast cancer [81].

Altogether, these important studies provided some mechanistic insight regarding RNF167 dysfunction in cancer cells. However, these same studies highlight the importance of further investigating the function and the Ub ligase activity of tumor-associated RNF167 variants.

\section{ZNRF4}

Zinc and Ring Finger 4 (ZNRF4, also referred to as Nixin) was first identified in 1999 when Fujii et al. isolated genes whose expression was induced in mouse spermatogenic cells [82]. At the time, they called the protein spermatic-specific RING zinc finger (sperizin) [82]. Using northern blot analysis, mouse sperizin was exclusively found in testis. The human ZNRF4 sequence (Uniprot Accession Q8WWF5) includes the characteristic domains of the family (Figure 2).

The sperizin gene expression was detected in pre-pubertal testis beginning at 23 days old, increased at 29 days old, and then declined in adult testis (35 days old), suggesting that it may be involved in mouse spermatogenesis [82]. Interestingly, sperizin expression was increased following a retinol treatment in vitamin A-deficient rat testes [83]. Vitamin $A$ is known to be critical in maintaining mammalian spermatogenesis and sperizin could be an important downstream protein of this cellular process [83]. Furthermore, to our knowledge, no study has specifically investigated the role of the human ZNRF4 protein in spermatogenesis, but it is worth noting that ZNRF4 RNA expression in humans appears to be restricted to the testis as well [61]. However, while single-nucleotide variations of ZNFR4 have been discovered in tumors, it should be noted that studies have yet to report the pathological impact of these variants.

\subsection{Calnexin}

While the overexpression of GFP-tagged sperizin (mouse protein) leads to a cytosolic localization in HeLa cells, the overexpression of ZNRF4-YFP (human protein) displays an ER localization in HeLa and HCT116 cells [82,84,85]. Accordingly, ZNRF4 is implicated in the degradation of calnexin, an ER-localized chaperone [84]. Importantly, the ectopic expression of WT, but not DN ZNRF4, reduces calnexin staining in HeLa cells [84]. The use of the proteasomal inhibitor MG132 demonstrated that ubiquitination of calnexin led to proteasomal degradation, confirming the important role that ZNRF4 plays in calnexin turnover [84].

\subsection{RIP2}

A recent human genome-wide RNAi screen was performed to find negative regulators of nucleotide-binding oligomerization domain 2 (NOD2)-induced nuclear factor- $\mathrm{KB}$ (NFКB) activation in HEK293T cells [85]. The authors discovered that ZNRF4 knockdown led to an increased response of NOD2-dependent NF- $\mathrm{KB}$ activation. Conversely, the ectopic expression of ZNRF4 in HEK293T led to a reduction in NOD2-induced NF- $\mathrm{KB}$ activation in a dose-dependent manner [85]. Using a DN ZNRF4 variant as a negative control, the authors confirmed that the overexpression of WT ZNRF4 led to reduced NOD2-dependent NF- $\mathrm{B}$ activation and identified receptor-interacting protein 2 (RIP2), a major signal integrator for the NOD1 and NOD2 pathways, as the substrate [85]. The treatment with MG132 
rescued RIP2 degradation when ZNRF4 was overexpressed, indicating that ubiquitination of RIP2 by ZNRF4 leads to proteasomal degradation. Importantly, this is consistent with the fact that ZNRF4 promotes K48-linked ubiquitination of RIP2 [85]. Additionally, the ZNRF4 knockdown in MPD-treated human monocyte-derived macrophages increased the secretion of cytokines, such as interleukin-8 (IL-8), tumor necrosis factor $\alpha$ (TNF- $\alpha$ ), and interleukin $1 \beta$ (IL-1 $\beta$ ) [85]. Research also demonstrated a role for ZNRF4 in NOD2-induced tolerance in vivo as ZNRF4 knockdown mice lost their ability to induce NOD2 tolerance when compared to WT mice [85]. Overall, these studies suggest that ZNRF4 has a function in various biological processes, including spermatogenesis, ER homeostasis and NOD2 signaling [82-85].

\section{Conclusions and Future Perspectives}

A lot of work has been done in the last 20 years to better understand the role of the human Godzilla homologues, RNF167, RNF13, and ZNRF4. Table 1 summarizes the biological function and pathological dysfunctions of these E3 ligases, as well as the known substrates and roles of their ubiquitination. However, many unanswered questions remain.

Table 1. Summary of the substrates, the role of their ubiquitination, and their known biological functions and pathological dysfunctions for each E3 ligase discussed in the current review.

\begin{tabular}{|c|c|c|c|c|}
\hline E3 Ligase & Substrate & Role of Ubiquitination & Biological Function & $\begin{array}{l}\text { Pathological } \\
\text { Dysfunction }\end{array}$ \\
\hline \multirow[t]{2}{*}{ Godzilla } & \multirow[t]{2}{*}{ Syb $[33,45]$} & Not determined (N.D.) & $\begin{array}{l}\text { Regulation of recycling endosome } \\
\text { trafficking [33] }\end{array}$ & N.D. \\
\hline & & N.D. & Wingless transcytosis [45] & N.D. \\
\hline \multirow{11}{*}{ RNF13 } & \multirow[t]{2}{*}{ N.D. } & N.D. & $\begin{array}{l}\text { Ectopic expression promotes } \\
\text { spontaneous growth of neurites in } \\
\text { PC12 cells [60] }\end{array}$ & N.D. \\
\hline & & N.D. & $\begin{array}{l}\text { mRNA expression increases with } \\
\text { dibuturyl-cAMP treatment in B35 } \\
\text { cells [47] }\end{array}$ & N.D. \\
\hline & \multirow[t]{2}{*}{ Snapin [62] } & \multirow{2}{*}{$\begin{array}{c}\text { K29-linked poly-Ub } \\
\text { increased expression [62] } \\
\text { N.D. }\end{array}$} & SNARE complex assembly [62] & $\begin{array}{l}\text { Mice display deficit in } \\
\text { learning [62] }\end{array}$ \\
\hline & & & Increased MMP-9 activity [49] & Cancer [49 66] \\
\hline & \multirow[t]{3}{*}{ N.D. } & N.D. & $\begin{array}{c}\text { Regulation of GM-CSF } \\
\text { concentration [66] }\end{array}$ & Cancer $[49,00]$ \\
\hline & & N.D. & $\begin{array}{l}\text { Altered endolysosomal system } \\
{[27,59]}\end{array}$ & $\begin{array}{c}\text { Developmental and } \\
\text { epileptic encephalopathy } \\
73 \text { [59] }\end{array}$ \\
\hline & & & & Cancer [27] \\
\hline & \multirow{3}{*}{$\begin{array}{l}\text { (Interacts but not } \\
\text { shown to be a } \\
\text { substrate) [48] }\end{array}$} & \multirow{3}{*}{ N.D. } & \multirow{3}{*}{ Regulation of ER stress [48] } & $\begin{array}{c}\text { Developmental and } \\
\text { epileptic encephalopathy } \\
73[74]\end{array}$ \\
\hline & & & & $\begin{array}{c}\text { Mouse model of } \\
\text { Parkinson's disease [73] }\end{array}$ \\
\hline & & & & $\begin{array}{l}\text { Atherosclerotic plaques } \\
\text { [72] }\end{array}$ \\
\hline & N.D. & N.D. & $\begin{array}{l}\text { Regulation of muscle cell } \\
\text { proliferation through regulation of } \\
\text { IL-4 and IL-6 }[65,68]\end{array}$ & N.D. \\
\hline
\end{tabular}


Table 1. Cont.

\begin{tabular}{|c|c|c|c|c|}
\hline E3 Ligase & Substrate & Role of Ubiquitination & Biological Function & $\begin{array}{l}\text { Pathological } \\
\text { Dysfunction }\end{array}$ \\
\hline \multirow{6}{*}{ RNF167 } & GluA2 $[76,77]$ & $\begin{array}{l}\text { Regulated surface } \\
\text { expression [76] }\end{array}$ & $\begin{array}{c}\text { Regulation of neuronal synaptic } \\
\text { strength [76] }\end{array}$ & N.D. \\
\hline & Vamp3 [33] & N.D. & $\begin{array}{c}\text { Regulation of recycling endosomes } \\
\text { [33] }\end{array}$ & N.D. \\
\hline & Arl8B [78] & $\begin{array}{l}\text { Degradation via the } \\
\text { proteasome-dependent } \\
\text { pathway [78] }\end{array}$ & Lysosomal positioning [78] & \multirow{4}{*}{ Cancer $[75,80,81]$} \\
\hline & N.D. & N.D. & Lysosomal exocytosis [80] & \\
\hline & CASTOR1 [81] & $\begin{array}{l}\text { K29-linked polyUb chain } \\
\text { Degradation via the } \\
\text { proteasome-dependent } \\
\text { pathway [81] }\end{array}$ & $\begin{array}{l}\text { Inhibition of mTORC1 activation } \\
\text { [81] }\end{array}$ & \\
\hline & TSSC5 [75] & $\begin{array}{c}\text { Degradation via the } \\
\text { proteasome-dependent } \\
\text { pathway [75] }\end{array}$ & $\begin{array}{l}\text { Delays G1-to-S transition in HeLa } \\
\text { cells [75] }\end{array}$ & \\
\hline \multirow{4}{*}{ ZNRF4 } & N.D. & N.D. & Spermatogenesis in mice? [83] & N.D. \\
\hline & Calnexin [84] & $\begin{array}{c}\text { Degradation via the } \\
\text { proteasome-dependent } \\
\text { pathway [84] }\end{array}$ & ER homeostasis [84] & N.D. \\
\hline & RIP2 [85] & $\begin{array}{l}\text { K48-linked poly-Ub } \\
\text { chain }\end{array}$ & Negatively regulates NOD2 & N.D. \\
\hline & & $\begin{array}{l}\text { Degradation via the } \\
\text { proteasome-dependent } \\
\text { pathway [85] }\end{array}$ & & \\
\hline
\end{tabular}

Over the last two decades, the use of high-throughput screening (HTS) has increased dramatically since it can repeatedly test thousands of samples per day [86]. For instance, Huttlin et al. expressed hundreds of FLAG-HA-tagged baits in HEK293T cells and combined immunopurification and mass spectrometry to identify interactors of these bait proteins [54]. As shown in Figure 3, multiple interactors for RNF167, RNF13, and ZNRF4 were found using either this method or a similar one. Interestingly, these Godzilla homologues all have in common interactions with the UBE2D family, UBE2E1, UBE2E3, and UBE2N, which can give information on the type of Ub linkage patterns these E3 ligases can perform (Figure 1) $[75,77,87]$. Although no specific molecular mechanisms can be revealed by using HTS, it can, however, offer a starting point by providing putative interactors. For example, while there is very limited information available for ZNRF4, other than the fact that its expression was linked to spermatogenesis in mice [82], it is still unclear whether this function applies to humans as well. Importantly, the discovery of Frizzled-6 (FZD6) as one of the interactors for ZNRF4 $[55,56]$ is quite intriguing since FZD6 knockout mice show a severe reduction in sperm counts $[88,89]$. Therefore, studies are needed in order to determine the validity of a highly speculative mechanism where ZNRF4's role in spermatogenesis may be through interaction or regulation of FZD6. 


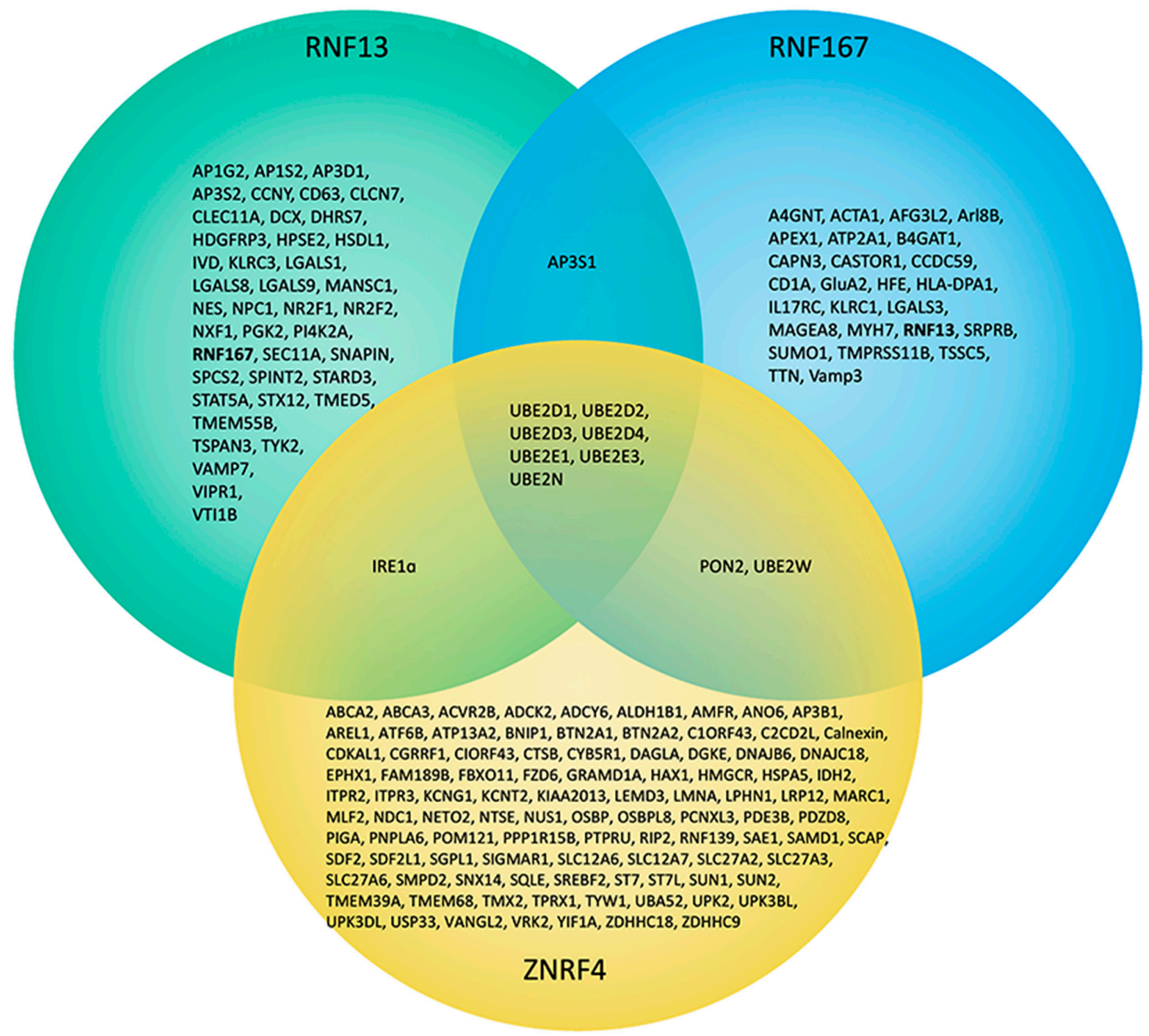

Figure 3. Venn diagram comparing the interactors of RNF13, RNF167, and ZNRF4. Interactors of RNF13 (green), RNF167 (blue), and ZNRF4 (yellow) discovered by both low and high throughput assays are displayed $[33,48,54-56,59,62,75-78,81,84,85,87,90-97]$.

In contrast to the limited knowledge regarding the interactors of ZNRF4 and its biological function, more information is available for both RNF167 and RNF13. For instance, we now know that RNF167 ubiquitinates TSSC5 leading to its degradation [75]. How RNF167 regulates and controls the cell cycle, however, or the consequence of a dysfunction in this pathway is unknown. It is possible that RNF167 has substrates in diverse subcellular locations and needs to be trafficked depending on the cellular context. Accordingly, RNF167 substrates Vamp3, Arl8B, and GluA2 have all been characterized to transit within the endolysosomal pathway. This suggests that RNF167 traffics to the endolysosomes via a mechanism that is anticipated to be similar to the reported interaction between the canonical di-leucine motif of RNF13 and AP-3 [59], which is supported by the fact that both RNF13 and RNF167 have AP3S1 as common interactor (Figure 3) [55,56]. Thus, it is possible that the di-leucine motif is required for the interaction with the AP complexes, while the PA domain might be critical for the interaction with proteins that allow the proper endosomal targeting of both RNF13 and RNF167. An interaction was also identified between ZNRF4 and IRE1 $\alpha$, which was previously demonstrated to interact with RNF13 (Figure 3) $[48,55,56]$. Although their respective intracellular localization differs across 
various experimental settings, it may be of interest to study how these two E3 ligases regulate the same protein, and if some type of redundancy exists between them.

Finally, we cannot overlook the multiple studies that have shown how the specific domains are important for endosomal and lysosomal localization. For example, cancerassociated RNF167 variants K97N and V98G in the PA domain led to mislocalized proteins $[27,80]$. Furthermore, in order to better understand how RNF167 and RNF13 are regulated, we must determine the impact of PTMs, such as ubiquitination and phosphorylation (Table 2). To our knowledge, a comprehensive molecular investigation of PTMs on RNF13 and RNF167 has not been reported, although it is known that RNF13 and RNF167 are glycosylated and that RNF13 is trafficked to the nucleus following PKC activation by PMA treatment [50]. Therefore, it would be interesting to evaluate if PKC phosphorylates, either T309, S319, or T380, on RNF13 to induce nuclear localization or if PKC acts through an intermediate effector. Hopefully, future studies will provide clearer mechanisms as to how RNF167 and RNF13 reach the endolysosomal compartment and how their Ub ligase activities regulate the vesicular dynamics and the degradation of the plasma membrane cargo. This is critical since the list of pathologies associated with RNF167 and RNF13 is growing.

Table 2. Information on gene and post-translational modifications of human homologues of Godzilla.

\begin{tabular}{cc}
\hline Gene & Post-Translational Modifications \\
\hline RNF167 & Ubiquitination: K97, K156, K210, K214, K223, K242, K266, K272 [98-101] \\
Methylation: R277 [102] \\
ID 26001 & $\begin{array}{c}\text { Phosphorylation: T288, S341, S345 [103] } \\
\text { Glycosylation: N33, N79 [76] }\end{array}$ \\
\hline RNF13 & Ubiquitination: K107, K224, K225, K230, K232, K233, K252, K265, K273, \\
ID 11342 & K275, K282 [98-101,104-106] \\
Position 3q25.1 & $\begin{array}{c}\text { Phosphorylation: T309, S319, T380 [103,107] } \\
\text { Glycosylation: N70, N75, N88 [49,108] }\end{array}$ \\
ZNRF4 & Phosphorylation: T70 [109] \\
ID 148066 & Glycosylation: N107, N152, N229 [84] \\
Position 19p13.3 & \\
\hline
\end{tabular}

Author Contributions: Conceptualization, V.C.C. and M.P.L.; Writing-Original Draft Preparation, V.C.C. and M.P.L.; Writing-Review \& Editing, V.C.C. and M.P.L.; Funding Acquisition, M.P.L. All authors have read and agree to the published version of the manuscript.

Funding: Scholarship was awarded to V.C.C. from the Centre d'Excellence en Recherche sur les Maladies Orphelines-Fondation Courtois (CERMO-FC) $(2020,2021)$. During the same period, the laboratory received funding from the American Epilepsy Society (Award ID 822781), from the Natural Sciences and Engineering Research Council of Canada (RGPIN-2017-05392), and from the CERMO-FC.

Institutional Review Board Statement: Not applicable.

Informed Consent Statement: Not applicable.

Data Availability Statement: Not applicable.

Acknowledgments: The authors thank Jennifer R. Crawford for editing the manuscript.

Conflicts of Interest: No competing interests declared. Funding sources had no role in study design or in the collection, analysis, and interpretation of data. 
Abbreviations

\begin{tabular}{|c|c|}
\hline AMPA & $\alpha$-amino-3-hydroxy-5-methyl-4-isoxazolepropionic acid \\
\hline AMPAR & AMPA receptor \\
\hline AMPAR-EPSC & Evoked excitatory postsynaptic AMPAR currents \\
\hline $\mathrm{AP}$ & Adaptor protein \\
\hline Arl8B & ADP-ribosylation factor-like protein $8 \mathrm{~B}$ \\
\hline ASK1 & Apoptosis signal-regulating kinase 1 \\
\hline C-RZF & Chicken RING zinc finger \\
\hline CASTOR1 & Cytosolic arginine sensor for mTORC1 subunit 1 \\
\hline CFM & Chicken fetal myoblasts \\
\hline $\mathrm{CHO}$ & Chinese hamster ovary \\
\hline CTX & Cardiotoxin \\
\hline DEE73 & Developmental and epileptic encephalopathy 73 \\
\hline $\mathrm{DN}$ & Dominant-negative \\
\hline DUB & Deubiquitinase \\
\hline E & Glutamic acid \\
\hline E1 & Ubiquitin-activating enzyme \\
\hline E2 & Ubiquitin-conjugating enzyme \\
\hline E3 & Ubiquitin ligase \\
\hline EEA1 & Early endosome antigen 1 \\
\hline EGFR & Epidermal growth factor receptor \\
\hline ER & Endoplasmic reticulum \\
\hline $\mathrm{ER}+$ & Estrogen receptor positive \\
\hline FZD6 & Frizzled-6 \\
\hline GM-CSF & Granulocyte macrophage colony-stimulating factor \\
\hline HECT & Homology to E6AP Carboxyl Terminus \\
\hline HEK293T & Human embryonic kidney 293 \\
\hline HER2+ & Human epidermal growth factor receptor 2 positive \\
\hline HTS & High-throughput screening \\
\hline IL-1 $\beta$ & Interleukin $1 \beta$ \\
\hline IL-4 & Interleukin-4 \\
\hline IL-6 & Interleukin-6 \\
\hline IL-8 & Interleukin-8 \\
\hline INM & Inner nuclear membrane \\
\hline IRE1 $\alpha$ & Inositol-requiring enzyme $1 \alpha$ \\
\hline JNK & c-Jun N-terminal kinase \\
\hline Lamp1 & Lysosomal-associated membrane protein 1 \\
\hline M6P & Mannose-6-Phosphate \\
\hline MARCH & Membrane-associated RING-CH \\
\hline MMP-9 & Matrix metallopeptidase 9 \\
\hline MPTP & 1-methyl-4-phenyl-1,2.3.6-tetrahydropyridine \\
\hline mTORC1 & Mammalian target of rapamycin complex 1 \\
\hline NF-кB & Nuclear factor- $\mathrm{kB}$ \\
\hline NLS & Nuclear localization signal \\
\hline NOD2 & Nucleotide-binding oligomerization domain 2 \\
\hline Ox-LDL & Oxidized low-density lipoprotein \\
\hline $\mathrm{P}$ & Proline \\
\hline PA-TM-RING & Protease-associated transmembrane RING \\
\hline PA & Protease-associated \\
\hline PDAC & Pancreatic ductal adenocarcinoma \\
\hline PI & Propidium iodide \\
\hline PKC & Protein kinase C \\
\hline PMA & Phorbol 12-myristate 13-acetate \\
\hline
\end{tabular}




\begin{tabular}{|c|c|}
\hline PTM & Post-translational modification \\
\hline RBR & RING-Between-RING \\
\hline RING & Really Interesting Novel Gene \\
\hline RIP2 & Receptor-interacting protein 2 \\
\hline RNF13 & Ring Finger Protein 13 \\
\hline RNF167 & Ring Finger Protein 167 \\
\hline S & Serine \\
\hline shRNF13 & Short hairpin RNA specific for RNF13 \\
\hline siRNA & Small interfering RNA \\
\hline SLO & Streptolysin-O \\
\hline SNAP-25 & Synaptosome associated protein 25 \\
\hline Snapin & SNARE-associated protein \\
\hline SNARE & Soluble N-ethylmaleimide-sensitive-factor Attachment protein Receptor \\
\hline SNV & Single-nucleotide variations \\
\hline $\mathrm{SP}$ & Signal peptide \\
\hline Sperizin & Spermatic-specific ring zinc finger \\
\hline STS & Staurosporine \\
\hline Syb & Synaptobrevin \\
\hline $\mathrm{T}$ & Threonine \\
\hline TA & Tibialis anterior \\
\hline TH-IR & Tyrosine hydroxylase-immunoreactive \\
\hline TM & Transmembrane \\
\hline $\mathrm{TNF}-\alpha$ & Tumor necrosis factor $\alpha$ \\
\hline TNF & Tumor necrosis factor \\
\hline TRAF2 & TNF receptor-associated factor 2 \\
\hline TRIM & Tripartite motif-containing \\
\hline TSSC5 & Tumor-Suppressing Subchromosomal Transferable Fragment cDNA \\
\hline $\mathrm{Ub}$ & Ubiquitin \\
\hline Vamp3 & Vesicle-associated membrane protein 3 \\
\hline WT & Wild type \\
\hline XBP1 & X-Box Binding Protein 1 \\
\hline ZNRF4 & Zinc and Ring Finger 4 \\
\hline
\end{tabular}

\section{References}

1. Mann, M.; Jensen, O.N. Proteomic analysis of post-translational modifications. Nat. Biotechnol. 2003, 21, 255-261. [CrossRef] [PubMed]

2. Liu, J.; Qian, C.; Cao, X. Post-Translational Modification Control of Innate Immunity. Immunity 2016, 45, 15-30. [CrossRef] [PubMed]

3. Komander, D.; Rape, M. The ubiquitin code. Annu. Rev. Biochem. 2012, 81, 203-229. [CrossRef] [PubMed]

4. Hicke, L.; Dunn, R. Regulation of membrane protein transport by ubiquitin and ubiquitin-binding proteins. Annu. Rev. Cell Dev. Biol. 2003, 19, 141-172. [CrossRef] [PubMed]

5. Ye, Y.; Rape, M. Building ubiquitin chains: E2 enzymes at work. Nat. Rev. Mol. Cell Biol. 2009, 10, 755-764. [CrossRef] [PubMed]

6. Zheng, Q.; Huang, T.; Zhang, L.; Zhou, Y.; Luo, H.; Xu, H.; Wang, X. Dysregulation of Ubiquitin-Proteasome System in Neurodegenerative Diseases. Front. Aging Neurosci. 2016, 8, 303. [CrossRef] [PubMed]

7. Swatek, K.N.; Komander, D. Ubiquitin modifications. Cell Res. 2016, 26, 399-422. [CrossRef] [PubMed]

8. van Wijk, S.J.L.; Fulda, S.; Dikic, I.; Heilemann, M. Visualizing ubiquitination in mammalian cells. EMBO Rep. 2019, 20, e46520. [CrossRef]

9. Behrends, C.; Harper, J.W. Constructing and decoding unconventional ubiquitin chains. Nat. Struct. Mol. Biol. 2011, 18, 520-528. [CrossRef]

10. Rahighi, S.; Ikeda, F.; Kawasaki, M.; Akutsu, M.; Suzuki, N.; Kato, R.; Kensche, T.; Uejima, T.; Bloor, S.; Komander, D.; et al. Specific recognition of linear ubiquitin chains by NEMO is important for NF-kappaB activation. Cell 2009, 136, 1098-1109. [CrossRef]

11. Noad, J.; von der Malsburg, A.; Pathe, C.; Michel, M.A.; Komander, D.; Randow, F. LUBAC-synthesized linear ubiquitin chains restrict cytosol-invading bacteria by activating autophagy and NF-кB. Nat. Microbiol. 2017, 2, 17063. [CrossRef] [PubMed] 
12. van Wijk, S.J.L.; Fricke, F.; Herhaus, L.; Gupta, J.; Hötte, K.; Pampaloni, F.; Grumati, P.; Kaulich, M.; Sou, Y.S.; Komatsu, M.; et al. Linear ubiquitination of cytosolic Salmonella Typhimurium activates NF-kB and restricts bacterial proliferation. Nat. Microbiol. 2017, 2, 17066. [CrossRef] [PubMed]

13. Tracz, M.; Bialek, W. Beyond K48 and K63: Non-canonical protein ubiquitination. Cell. Mol. Biol. Lett. 2021, 26, 1. [CrossRef] [PubMed]

14. van Huizen, M.; Kikkert, M. The Role of Atypical Ubiquitin Chains in the Regulation of the Antiviral Innate Immune Response. Front. Cell Dev. Biol. 2020, 7, 392. [CrossRef]

15. Sigismund, S.; Polo, S.; Di Fiore, P.P. Signaling through monoubiquitination. Curr. Top Microbiol. Immunol. 2004, 286, 149-185. [CrossRef]

16. Sun, L.; Chen, Z.J. The novel functions of ubiquitination in signaling. Curr. Opin. Cell Biol. 2004, 16, 119-126. [CrossRef]

17. Kravtsova-Ivantsiv, Y.; Sommer, T.; Ciechanover, A. The lysine48-based polyubiquitin chain proteasomal signal: Not a single child anymore. Angew. Chem. Int. Ed. Engl. 2013, 52, 192-198. [CrossRef]

18. Chen, Z.J. Ubiquitin signalling in the NF-kappaB pathway. Nat. Cell Biol. 2005, 7, 758-765. [CrossRef]

19. Suresh, B.; Lee, J.; Kim, H.; Ramakrishna, S. Regulation of pluripotency and differentiation by deubiquitinating enzymes. Cell Death Differ. 2016, 23, 1257-1264. [CrossRef]

20. Chastagner, P.; Israël, A.; Brou, C. Itch/AIP4 mediates Deltex degradation through the formation of K29-linked polyubiquitin chains. EMBO Rep. 2006, 7, 1147-1153. [CrossRef]

21. Matsumoto, M.L.; Wickliffe, K.E.; Dong, K.C.; Yu, C.; Bosanac, I.; Bustos, D.; Phu, L.; Kirkpatrick, D.S.; Hymowitz, S.G.; Rape, M.; et al. K11-linked polyubiquitination in cell cycle control revealed by a K11 linkage-specific antibody. Mol. Cell 2010, 39, 477-484 [CrossRef] [PubMed]

22. Jiang, Y.H.; Beaudet, A.L. Human disorders of ubiquitination and proteasomal degradation. Curr. Opin. Pediatr. 2004, 16, 419-426. [CrossRef]

23. Spratt, D.E.; Walden, H.; Shaw, G.S. RBR E3 ubiquitin ligases: New structures, new insights, new questions. Biochem. J. 2014, 458, 421-437. [CrossRef]

24. Li, W.; Bengtson, M.H.; Ulbrich, A.; Matsuda, A.; Reddy, V.A.; Orth, A.; Chanda, S.K.; Batalov, S.; Joazeiro, C.A.P. Genome-wide and functional annotation of human E3 ubiquitin ligases identifies MULAN, a mitochondrial E3 that regulates the organelle's dynamics and signaling. PLoS ONE 2008, 3, e1487. [CrossRef] [PubMed]

25. Metzger, M.B.; Hristova, V.A.; Weissman, A.M. HECT and RING finger families of E3 ubiquitin ligases at a glance. J. Cell Sci. 2012, 125, 531-537. [CrossRef] [PubMed]

26. Nakamura, N. The Role of the Transmembrane RING Finger Proteins in Cellular and Organelle Function. Membranes 2011, 1, 354-393. [CrossRef] [PubMed]

27. van Dijk, J.R.; Yamazaki, Y.; Palmer, R.H. Tumour-associated mutations of PA-TM-RING ubiquitin ligases RNF167/RNF13 identify the PA domain as a determinant for endosomal localization. Biochem. J. 2014, 459, 27-36. [CrossRef]

28. Nakai, K.; Imai, K. Prediction of Protein Localization. In Encyclopedia of Bioinformatics and Computational Biology; Ranganathan, S., Gribskov, M., Nakai, K., Schönbach, C., Eds.; Academic Press: Oxford, UK, 2019; pp. 53-59. [CrossRef]

29. Mahon, P.; Bateman, A. The PA domain: A protease-associated domain. Protein Sci. 2000, 9, 1930-1934. [CrossRef]

30. Luo, X.; Hofmann, K. The protease-associated domain: A homology domain associated with multiple classes of proteases. Trends Biochem. Sci. 2001, 26, 147-148. [CrossRef]

31. Wayne Albers, R.R.W. Chapter 2-Cell Membrane Structures and Functions. In Basic Neurochemistry, 8th ed.; Brady, S.T., Siegel, G.J., Albers, R.W., Price, D.L., Eds.; Academic Press: New York, NY, USA, 2012; pp. 26-39. [CrossRef]

32. Jenn, R.C. A Systematic Analysis of Human Transmembrane E3-RING Proteins. Doctoral Dissertation, University of Liverpool, Liverpool, UK, 2011.

33. Yamazaki, Y.; Schönherr, C.; Varshney, G.K.; Dogru, M.; Hallberg, B.; Palmer, R.H. Goliath family E3 ligases regulate the recycling endosome pathway via VAMP3 ubiquitylation. EMBO J. 2013, 32, 524-537. [CrossRef]

34. Côté, S.; Preiss, A.; Haller, J.; Schuh, R.; Kienlin, A.; Seifert, E.; Jäckle, H. The gooseberry-zipper region of Drosophila: Five genes encode different spatially restricted transcripts in the embryo. EMBO J. 1987, 6, 2793-2801. [CrossRef] [PubMed]

35. Bouchard, M.L.; Côté, S. The Drosophila melanogaster developmental gene g1 encodes a variant zinc-finger-motif protein. Gene 1993, 125, 205-209. [CrossRef]

36. Artero, R.; Furlong, E.E.; Beckett, K.; Scott, M.P.; Baylies, M. Notch and Ras signaling pathway effector genes expressed in fusion competent and founder cells during Drosophila myogenesis. Development 2003, 130, 6257-6272. [CrossRef] [PubMed]

37. Ren, J.; Wen, L.; Gao, X.; Jin, C.; Xue, Y.; Yao, X. DOG 1.0: Illustrator of protein domain structures. Cell Res. 2009, 19, 271-273. [CrossRef] [PubMed]

38. Anandasabapathy, N.; Ford, G.S.; Bloom, D.; Holness, C.; Paragas, V.; Seroogy, C.; Skrenta, H.; Hollenhorst, M.; Fathman, C.G.; Soares, L. GRAIL: An E3 ubiquitin ligase that inhibits cytokine gene transcription is expressed in anergic CD4+ T cells. Immunity 2003, 18, 535-547. [CrossRef]

39. Soares, L.; Seroogy, C.; Skrenta, H.; Anandasabapathy, N.; Lovelace, P.; Chung, C.D.; Engleman, E.; Fathman, C.G. Two isoforms of otubain 1 regulate T cell anergy via GRAIL. Nat. Immunol. 2004, 5, 45-54. [CrossRef]

40. Heissmeyer, V.; Macián, F.; Im, S.H.; Varma, R.; Feske, S.; Venuprasad, K.; Gu, H.; Liu, Y.C.; Dustin, M.L.; Rao, A. Calcineurin imposes T cell unresponsiveness through targeted proteolysis of signaling proteins. Nat. Immunol. 2004, 5, 255-265. [CrossRef] 
41. Adams, M.D.; Celniker, S.E.; Holt, R.A.; Evans, C.A.; Gocayne, J.D.; Amanatides, P.G.; Scherer, S.E.; Li, P.W.; Hoskins, R.A.; Galle, R.F.; et al. The genome sequence of Drosophila melanogaster. Science 2000, 287, 2185-2195. [CrossRef]

42. McMahon, H.T.; Ushkaryov, Y.A.; Edelmann, L.; Link, E.; Binz, T.; Niemann, H.; Jahn, R.; Südhof, T.C. Cellubrevin is a ubiquitous tetanus-toxin substrate homologous to a putative synaptic vesicle fusion protein. Nature 1993, 364, 346-349. [CrossRef]

43. Galli, T.; Chilcote, T.; Mundigl, O.; Binz, T.; Niemann, H.; De Camilli, P. Tetanus toxin-mediated cleavage of cellubrevin impairs exocytosis of transferrin receptor-containing vesicles in CHO cells. J. Cell Biol. 1994, 125, 1015-1024. [CrossRef]

44. Tuma, P.L.; Hubbard, A.L. Transcytosis: Crossing Cellular Barriers. Physiol. Rev. 2003, 83, 871-932. [CrossRef] [PubMed]

45. Yamazaki, Y.; Palmer, L.; Alexandre, C.; Kakugawa, S.; Beckett, K.; Gaugue, I.; Palmer, R.H.; Vincent, J.P. Godzilla-dependent transcytosis promotes Wingless signalling in Drosophila wing imaginal discs. Nat. Cell. Biol. 2016, 18, 451-457. [CrossRef] [PubMed]

46. Tranque, P.; Crossin, K.L.; Cirelli, C.; Edelman, G.M.; Mauro, V.P. Identification and characterization of a RING zinc finger gene (C-RZF) expressed in chicken embryo cells. Proc. Natl. Acad. Sci. USA 1996, 93, 3105-3109. [CrossRef] [PubMed]

47. Bocock, J.P.; Carmicle, S.; Chhotani, S.; Ruffolo, M.R.; Chu, H.; Erickson, A.H. The PA-TM-RING protein RING finger protein 13 is an endosomal integral membrane E3 ubiquitin ligase whose RING finger domain is released to the cytoplasm by proteolysis. FEBS J. 2009, 276, 1860-1877. [CrossRef] [PubMed]

48. Arshad, M.; Ye, Z.; Gu, X.; Wong, C.K.; Liu, Y.; Li, D.; Zhou, L.; Zhang, Y.; Bay, W.P.; Yu, V.C.; et al. RNF13, a RING finger protein, mediates endoplasmic reticulum stress-induced apoptosis through the inositol-requiring enzyme (IRE1 $\alpha$ )/c-Jun NH2-terminal kinase pathway. J. Biol. Chem. 2013, 288, 8726-8736. [CrossRef] [PubMed]

49. Zhang, Q.; Meng, Y.; Zhang, L.; Chen, J.; Zhu, D. RNF13: A novel RING-type ubiquitin ligase over-expressed in pancreatic cancer Cell Res. 2009, 19, 348-357. [CrossRef]

50. Bocock, J.P.; Carmicle, S.; Madamba, E.; Erickson, A.H. Nuclear targeting of an endosomal E3 ubiquitin ligase. Traffic 2010, 11, 756-766. [CrossRef]

51. Rogers, S.; Wells, R.; Rechsteiner, M. Amino Acid Sequences Common to Rapidly Degraded Proteins: The PEST Hypothesis. Science 1986, 234, 364-368. [CrossRef]

52. Bonifacino, J.S.; Traub, L.M. Signals for sorting of transmembrane proteins to endosomes and lysosomes. Annu. Rev. Biochem. 2003, 72, 395-447. [CrossRef]

53. Boehm, M.; Bonifacino, J.S. Adaptins: The final recount. Mol. Biol. Cell 2001, 12, 2907-2920. [CrossRef]

54. Huttlin, E.L.; Ting, L.; Bruckner, R.J.; Gebreab, F.; Gygi, M.P.; Szpyt, J.; Tam, S.; Zarraga, G.; Colby, G.; Baltier, K.; et al. The BioPlex Network: A Systematic Exploration of the Human Interactome. Cell 2015, 162, 425-440. [CrossRef] [PubMed]

55. Huttlin, E.L.; Bruckner, R.J.; Paulo, J.A.; Cannon, J.R.; Ting, L.; Baltier, K.; Colby, G.; Gebreab, F.; Gygi, M.P.; Parzen, H.; et al. Architecture of the human interactome defines protein communities and disease networks. Nature 2017, 545, 505-509. [CrossRef] [PubMed]

56. Huttlin, E.L.; Bruckner, R.J.; Navarrete-Perea, J.; Cannon, J.R.; Baltier, K.; Gebreab, F.; Gygi, M.P.; Thornock, A.; Zarraga, G.; Tam, S.; et al. Dual proteome-scale networks reveal cell-specific remodeling of the human interactome. Cell 2021, 184, 3022-3040.e28. [CrossRef] [PubMed]

57. Sanger, A.; Hirst, J.; Davies, A.K.; Robinson, M.S. Adaptor protein complexes and disease at a glance. J. Cell Sci. 2019, 132, jcs222992. [CrossRef]

58. Park, S.Y.; Guo, X. Adaptor protein complexes and intracellular transport. Biosci. Rep. 2014, 34, e00123. [CrossRef]

59. Cabana, V.C.; Bouchard, A.Y.; Sénécal, A.M.; Ghilarducci, K.; Kourrich, S.; Cappadocia, L.; Lussier, M.P. RNF13 Dileucine Motif Variants L311S and L312P Interfere with Endosomal Localization and AP-3 Complex Association. Cells 2021, 10, 3063. [CrossRef]

60. Saito, S.; Honma, K.; Kita-Matsuo, H.; Ochiya, T.; Kato, K. Gene expression profiling of cerebellar development with highthroughput functional analysis. Physiol. Genom. 2005, 22, 8-13. [CrossRef]

61. Kaneko, M.; Iwase, I.; Yamasaki, Y.; Takai, T.; Wu, Y.; Kanemoto, S.; Matsuhisa, K.; Asada, R.; Okuma, Y.; Watanabe, T.; et al. Genome-wide identification and gene expression profiling of ubiquitin ligases for endoplasmic reticulum protein degradation. Sci. Rep. 2016, 6, 30955. [CrossRef]

62. Zhang, Q.; Li, Y.; Zhang, L.; Yang, N.; Meng, J.; Zuo, P.; Zhang, Y.; Chen, J.; Wang, L.; Gao, X.; et al. E3 ubiquitin ligase RNF13 involves spatial learning and assembly of the SNARE complex. Cell Mol. Life Sci. 2013, 70, 153-165. [CrossRef]

63. Al-Hakim, A.K.; Zagorska, A.; Chapman, L.; Deak, M.; Peggie, M.; Alessi, D.R. Control of AMPK-related kinases by USP9X and atypical Lys(29)/Lys(33)-linked polyubiquitin chains. Biochem. J. 2008, 411, 249-260. [CrossRef]

64. Jin, X.; Cheng, H.; Chen, J.; Zhu, D. RNF13: An emerging RING finger ubiquitin ligase important in cell proliferation. FEBS J. 2011, 278, 78-84. [CrossRef] [PubMed]

65. Zhang, Q.; Wang, K.; Zhang, Y.; Meng, J.; Yu, F.; Chen, Y.; Zhu, D. The myostatin-induced E3 ubiquitin ligase RNF13 negatively regulates the proliferation of chicken myoblasts. FEBS J. 2010, 277, 466-476. [CrossRef] [PubMed]

66. Cheng, H.; Wang, A.; Meng, J.; Zhang, Y.; Zhu, D. Enhanced metastasis in RNF13 knockout mice is mediated by a reduction in GM-CSF levels. Protein Cell 2015, 6, 746-756. [CrossRef] [PubMed]

67. Arshad, A.; Gu, X.; Arshad, M. RNF13 protein regulates endoplasmic reticulum stress induced apoptosis in dopaminergic SH-SY5Y cells by enhancing IRE1 $\alpha$ stability. J. Recept Signal Transduct. Res. 2014, 34, 119-124. [CrossRef]

68. Meng, J.; Zou, X.; Wu, R.; Zhong, R.; Zhu, D.; Zhang, Y. Accelerated regeneration of the skeletal muscle in RNF13-knockout mice is mediated by macrophage-secreted IL-4/IL-6. Protein Cell 2014, 5, 235-247. [CrossRef] 
69. Ness, C.; Katta, K.; Garred, Ø.; Kumar, T.; Olstad, O.K.; Petrovski, G.; Moe, M.C.; Noer, A. Integrated differential DNA methylation and gene expression of formalin-fixed paraffin-embedded uveal melanoma specimens identifies genes associated with early metastasis and poor prognosis. Exp. Eye Res. 2020, 203, 108426. [CrossRef]

70. Zhang, K.; Qin, X.; Zhou, X.; Zhou, J.; Wen, P.; Chen, S.; Wu, M.; Wu, Y.; Zhuang, J. Analysis of genes and underlying mechanisms involved in foam cells formation and atherosclerosis development. Peer] 2020, 8, e10336. [CrossRef]

71. Bazan-Socha, S.; Buregwa-Czuma, S.; Jakiela, B.; Zareba, L.; Zawlik, I.; Myszka, A.; Soja, J.; Okon, K.; Zarychta, J.; Kozlik, P.; et al. Reticular Basement Membrane Thickness Is Associated with Growth- and Fibrosis-Promoting Airway Transcriptome Profile-Study in Asthma Patients. Int. J. Mol. Sci. 2021, 22, 998. [CrossRef]

72. Huang, D.; Liu, Y.; Gao, L.; Wei, X.; Xu, Y.; Cai, R.; Su, Q. MiR-32-3p Regulates Myocardial Injury Induced by Microembolism and Microvascular Obstruction by Targeting RNF13 to Regulate the Stability of Atherosclerotic Plaques. J. Cardiovasc. Transl. Res. 2021. [CrossRef]

73. Ji, M.; Niu, S.; Guo, J.; Mi, H.; Jiang, P. Silencing RNF13 Alleviates Parkinson's Disease-like Problems in Mouse Models by Regulating the Endoplasmic Reticulum Stress-Mediated IRE1 $\alpha$-TRAF2-ASK1-JNK Pathway. J. Mol. Neurosci. 2020, 70, 1977-1986. [CrossRef]

74. Edvardson, S.; Nicolae, C.M.; Noh, G.J.; Burton, J.E.; Punzi, G.; Shaag, A.; Bischetsrieder, J.; De Grassi, A.; Pierri, C.L.; Elpeleg, O.; et al. Heterozygous RNF13 Gain-of-Function Variants Are Associated with Congenital Microcephaly, Epileptic Encephalopathy, Blindness, and Failure to Thrive. Am. J. Hum. Genet. 2019, 104, 179-185. [CrossRef] [PubMed]

75. Yamada, H.Y.; Gorbsky, G.J. Tumor suppressor candidate TSSC5 is regulated by UbcH6 and a novel ubiquitin ligase RING105. Oncogene 2006, 25, 1330-1339. [CrossRef] [PubMed]

76. Lussier, M.P.; Herring, B.E.; Nasu-Nishimura, Y.; Neutzner, A.; Karbowski, M.; Youle, R.J.; Nicoll, R.A.; Roche, K.W. Ubiquitin ligase RNF167 regulates AMPA receptor-mediated synaptic transmission. Proc. Natl. Acad. Sci. USA 2012, 109, 19426-19431. [CrossRef] [PubMed]

77. Ghilarducci, K.; Cabana, V.C.; Desroches, C.; Chabi, K.; Bourgault, S.; Cappadocia, L.; Lussier, M.P. Functional interaction of ubiquitin ligase RNF167 with UBE2D1 and UBE2N promotes ubiquitination of AMPA receptor. FEBS J. 2021, 288, $4849-4868$. [CrossRef] [PubMed]

78. Deshar, R.; Moon, S.; Yoo, W.; Cho, E.B.; Yoon, S.K.; Yoon, J.B. RNF167 targets Arl8B for degradation to regulate lysosome positioning and endocytic trafficking. FEBS J. 2016, 283, 4583-4599. [CrossRef] [PubMed]

79. Widagdo, J.; Chai, Y.J.; Ridder, M.C.; Chau, Y.Q.; Johnson, R.C.; Sah, P.; Huganir, R.L.; Anggono, V. Activity-Dependent Ubiquitination of GluA1 and GluA2 Regulates AMPA Receptor Intracellular Sorting and Degradation. Cell Rep. 2015, 10, 783-795. [CrossRef] [PubMed]

80. Nair, S.V.; Narendradev, N.D.; Nambiar, R.P.; Kumar, R.; Srinivasula, S.M. Naturally occurring and tumor-associated variants of RNF167 promote lysosomal exocytosis and plasma membrane resealing. J. Cell Sci. 2020, 133, jcs239335. [CrossRef]

81. Li, T.; Wang, X.; Ju, E.; da Silva, S.R.; Chen, L.; Zhang, X.; Wei, S.; Gao, S.J. RNF167 activates mTORC1 and promotes tumorigenesis by targeting CASTOR1 for ubiquitination and degradation. Nat. Commun. 2021, 12, 1055. [CrossRef]

82. Fujii, T.; Tamura, K.; Copeland, N.G.; Gilbert, D.J.; Jenkins, N.A.; Yomogida, K.; Tanaka, H.; Nishimune, Y.; Nojima, H.; Abiko, Y Sperizin is a murine RING zinc-finger protein specifically expressed in Haploid germ cells. Genomics 1999, 57, 94-101. [CrossRef]

83. Glozak, M.A.; Li, Y.; Reuille, R.; Kim, K.H.; Vo, M.-N.; Rogers, M.B. Trapping and Characterization of Novel Retinoid Response Elements. Mol. Endocrinol. 2003, 17, 27-41. [CrossRef]

84. Neutzner, A.; Neutzner, M.; Benischke, A.S.; Ryu, S.W.; Frank, S.; Youle, R.J.; Karbowski, M. A systematic search for endoplasmic reticulum (ER) membrane-associated RING finger proteins identifies Nixin/ZNRF4 as a regulator of calnexin stability and ER homeostasis. J. Biol. Chem. 2011, 286, 8633-8643. [CrossRef] [PubMed]

85. Bist, P.; Cheong, W.S.; Ng, A.; Dikshit, N.; Kim, B.-H.; Pulloor, N.K.; Khameneh, H.J.; Hedl, M.; Shenoy, A.R.; Balamuralidhar, V.; et al. E3 Ubiquitin ligase ZNRF4 negatively regulates NOD2 signalling and induces tolerance to MDP. Nat. Commun. 2017, 8 , 15865. [CrossRef] [PubMed]

86. Attene-Ramos, M.S.; Austin, C.P.; Xia, M. High Throughput Screening. In Encyclopedia of Toxicology, 3rd ed.; Wexler, P., Ed.; Academic Press: Oxford, UK, 2014; pp. 916-917. [CrossRef]

87. van Wijk, S.J.L.; de Vries, S.J.; Kemmeren, P.; Huang, A.; Boelens, R.; Bonvin, A.M.J.J.; Timmers, H.T.M. A comprehensive framework of E2-RING E3 interactions of the human ubiquitin-proteasome system. Mol. Syst. Biol. 2009, 5, 295. [CrossRef] [PubMed]

88. Wang, Y.; Guo, N.; Nathans, J. The role of Frizzled3 and Frizzled6 in neural tube closure and in the planar polarity of inner-ear sensory hair cells. J. Neurosci. 2006, 26, 2147-2156. [CrossRef] [PubMed]

89. Stuebner, S.; Faus-Kessler, T.; Fischer, T.; Wurst, W.; Prakash, N. Fzd3 and Fzd6 deficiency results in a severe midbrain morphogenesis defect. Dev. Dyn. 2010, 239, 246-260. [CrossRef] [PubMed]

90. Blandin, G.; Marchand, S.; Charton, K.; Danièle, N.; Gicquel, E.; Boucheteil, J.-B.; Bentaib, A.; Barrault, L.; Stockholm, D.; Bartoli, M.; et al. A human skeletal muscle interactome centered on proteins involved in muscular dystrophies: LGMD interactome. Skelet. Muscle 2013, 3, 3. [CrossRef]

91. Antoniali, G.; Serra, F.; Lirussi, L.; Tanaka, M.; D’Ambrosio, C.; Zhang, S.; Radovic, S.; Dalla, E.; Ciani, Y.; Scaloni, A.; et al. Mammalian APE1 controls miRNA processing and its interactome is linked to cancer RNA metabolism. Nat. Commun. 2017, 8, 797. [CrossRef] 
92. Ewing, R.M.; Chu, P.; Elisma, F.; Li, H.; Taylor, P.; Climie, S.; McBroom-Cerajewski, L.; Robinson, M.D.; O'Connor, L.; Li, M.; et al. Large-scale mapping of human protein-protein interactions by mass spectrometry. Mol. Syst. Biol. 2007, 3, 89. [CrossRef]

93. Hein, M.Y.; Hubner, N.C.; Poser, I.; Cox, J.; Nagaraj, N.; Toyoda, Y.; Gak, I.A.; Weisswange, I.; Mansfeld, J.; Buchholz, F.; et al. A Human Interactome in Three Quantitative Dimensions Organized by Stoichiometries and Abundances. Cell 2015, 163, 712-723. [CrossRef]

94. Castello, A.; Fischer, B.; Eichelbaum, K.; Horos, R.; Beckmann, B.M.; Strein, C.; Davey, N.E.; Humphreys, D.T.; Preiss, T.; Steinmetz, L.M.; et al. Insights into RNA biology from an atlas of mammalian mRNA-binding proteins. Cell 2012, 149, 1393-1406. [CrossRef]

95. van den Boomen, D.J.H.; Sienkiewicz, A.; Berlin, I.; Jongsma, M.L.M.; van Elsland, D.M.; Luzio, J.P.; Neefjes, J.J.C.; Lehner, P.J. A trimeric Rab7 GEF controls NPC1-dependent lysosomal cholesterol export. Nat. Commun. 2020, 11, 5559. [CrossRef] [PubMed]

96. Luck, K.; Kim, D.-K.; Lambourne, L.; Spirohn, K.; Begg, B.E.; Bian, W.; Brignall, R.; Cafarelli, T.; Campos-Laborie, F.J.; Charloteaux, B.; et al. A reference map of the human binary protein interactome. Nature 2020, 580, 402-408. [CrossRef] [PubMed]

97. Fenech, E.J.; Lari, F.; Charles, P.D.; Fischer, R.; Laétitia-Thézénas, M.; Bagola, K.; Paton, A.W.; Paton, J.C.; Gyrd-Hansen, M.; Kessler, B.M.; et al. Interaction mapping of endoplasmic reticulum ubiquitin ligases identifies modulators of innate immune signalling. Elife 2020, 9, e57306. [CrossRef] [PubMed]

98. Udeshi, N.D.; Svinkina, T.; Mertins, P.; Kuhn, E.; Mani, D.R.; Qiao, J.W.; Carr, S.A. Refined preparation and use of anti-diglycine

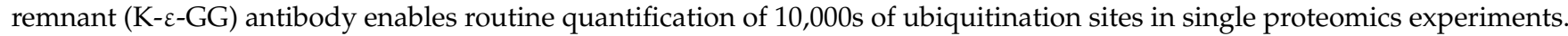
Mol. Cell Proteom. 2013, 12, 825-831. [CrossRef]

99. Akimov, V.; Barrio-Hernandez, I.; Hansen, S.V.F.; Hallenborg, P.; Pedersen, A.K.; Bekker-Jensen, D.B.; Puglia, M.; Christensen, S.D.K.; Vanselow, J.T.; Nielsen, M.M.; et al. UbiSite approach for comprehensive mapping of lysine and N-terminal ubiquitination sites. Nat. Struct. Mol. Biol. 2018, 25, 631-640. [CrossRef]

100. Beltrao, P.; Albanèse, V.; Kenner, L.R.; Swaney, D.L.; Burlingame, A.; Villén, J.; Lim, W.A.; Fraser, J.S.; Frydman, J.; Krogan, N.J Systematic functional prioritization of protein posttranslational modifications. Cell 2012, 150, 413-425. [CrossRef]

101. Li, W.; Wang, H.; Yang, Y.; Zhao, T.; Zhang, Z.; Tian, Y.; Shi, Z.; Peng, X.; Li, F.; Feng, Y.; et al. Integrative Analysis of Proteome and Ubiquitylome Reveals Unique Features of Lysosomal and Endocytic Pathways in Gefitinib-Resistant Non-Small Cell Lung Cancer Cells. Proteomics 2018, 18, e1700388. [CrossRef]

102. Larsen, S.C.; Sylvestersen, K.B.; Mund, A.; Lyon, D.; Mullari, M.; Madsen, M.V.; Daniel, J.A.; Jensen, L.J.; Nielsen, M.L. Proteomewide analysis of arginine monomethylation reveals widespread occurrence in human cells. Sci. Signal. 2016, 9, rs9. [CrossRef]

103. Mertins, P.; Mani, D.R.; Ruggles, K.V.; Gillette, M.A.; Clauser, K.R.; Wang, P.; Wang, X.; Qiao, J.W.; Cao, S.; Petralia, F.; et al. Proteogenomics connects somatic mutations to signalling in breast cancer. Nature 2016, 534, 55-62. [CrossRef]

104. Stukalov, A.; Girault, V.; Grass, V.; Karayel, O.; Bergant, V.; Urban, C.; Haas, D.A.; Huang, Y.; Oubraham, L.; Wang, A.; et al. Multilevel proteomics reveals host perturbations by SARS-CoV-2 and SARS-CoV. Nature 2021, 594, 246-252. [CrossRef]

105. Zhang, H.; Zheng, H.; Zhu, J.; Dong, Q.; Wang, J.; Fan, H.; Chen, Y.; Zhang, X.; Han, X.; Li, Q.; et al. Ubiquitin-Modified Proteome of SARS-CoV-2-Infected Host Cells Reveals Insights into Virus-Host Interaction and Pathogenesis. J. Proteome Res. 2021, 20, 2224-2239. [CrossRef] [PubMed]

106. Renaudin, X.; Guervilly, J.H.; Aoufouchi, S.; Rosselli, F. Proteomic analysis reveals a FANCA-modulated neddylation pathway involved in CXCR5 membrane targeting and cell mobility. J. Cell Sci. 2014, 127, 3546-3554. [CrossRef] [PubMed]

107. Bian, Y.; Song, C.; Cheng, K.; Dong, M.; Wang, F.; Huang, J.; Sun, D.; Wang, L.; Ye, M.; Zou, H. An enzyme assisted RP-RPLC approach for in-depth analysis of human liver phosphoproteome. J. Proteom. 2014, 96, 253-262. [CrossRef] [PubMed]

108. Deeb, S.J.; Cox, J.; Schmidt-Supprian, M.; Mann, M. N-linked glycosylation enrichment for in-depth cell surface proteomics of diffuse large B-cell lymphoma subtypes. Mol. Cell Proteom. 2014, 13, 240-251. [CrossRef]

109. Bordoli, M.R.; Yum, J.; Breitkopf, S.B.; Thon, J.N.; Italiano, J.E., Jr.; Xiao, J.; Worby, C.; Wong, S.K.; Lin, G.; Edenius, M.; et al. A secreted tyrosine kinase acts in the extracellular environment. Cell 2014, 158, 1033-1044. [CrossRef] 